\title{
Does the Intramolecular Hydrogen Bond Affect the Spectroscopic Properties of Bicyclic Diazole Heterocycles?
}

\author{
Paweł Misiak, ${ }^{1}$ Alina T. Dubis, ${ }^{1}$ and Andrzej Lapiński $\mathbb{D}^{2}$ \\ ${ }^{1}$ Institute of Chemistry, University of Bialystok, Ciołkowskiego 1K, 15-245 Bialystok, Poland \\ ${ }^{2}$ Institute of Molecular Physics, Polish Academy of Sciences, Smoluchowskiego 17, 60-179 Poznan, Poland \\ Correspondence should be addressed to Andrzej Łapiński; lapinski@ifmpan.poznan.pl
}

Received 28 November 2017; Revised 14 February 2018; Accepted 20 February 2018; Published 2 May 2018

Academic Editor: Renata Diniz

Copyright (C) 2018 Paweł Misiak et al. This is an open access article distributed under the Creative Commons Attribution License, which permits unrestricted use, distribution, and reproduction in any medium, provided the original work is properly cited.

\begin{abstract}
The formation of an intramolecular hydrogen bond in pyrrolo[1,2-a]pyrazin-1(2H)-one bicyclic diazoles was analyzed, and the influence of $\mathrm{N}$-substitution on HB formation is discussed in this study. B3LYP/aug-cc-pVDZ calculations were performed for the diazole, and the quantum theory of atoms in molecules (QTAIM) approach as well as the natural bond orbital (NBO) method was applied to analyze the strength of this interaction. It was found that the intramolecular hydrogen bond that closes an extra ring between the $\mathrm{C}=\mathrm{O}$ proton acceptor group and the $\mathrm{CH}$ proton donor, that is, $\mathrm{C}=\mathrm{O} \cdots \mathrm{H}-\mathrm{C}$, influences the spectroscopic properties of pyrrolopyrazine bicyclic diazoles, particularly the carbonyl frequencies. The influence of $N$-substitution on the aromaticity of heterocyclic rings is also discussed in this report.
\end{abstract}

\section{Introduction}

Pyrrolo[1,2-a]pyrazin-1(2H)-ones are an important class of natural organic compounds synthesized by many grassassociated endophytic fungi $[1,2]$. Symbiotic plants activate a defense reaction which allows the host plant to be protected against infection [3]. The ecological significance of pyrrolopyrazinones is related to their feeding deterrent activity. These alkaloids produced by endophytes provide protection of the host plant from herbivores as found in a large number of grass/endophyte associations [4]. A recent study has shown that peramine is transported from the endophyte into plant intercellular space where it is metabolized or removed via guttation fluid [2]. In the field of applied ecology, it is important to recognize natural chemical agents that control herbivorous insects [5]. Due to these properties, pyrrolopyrazinones can be used as structural models for studying the release mechanism, metabolism, structure of chemical compounds removed from plant tissues, and the mechanism of anti-insect activity [6].

An attempt has been made previously to identify spectroscopic properties of some pyrrolopyrazinones $[7,8]$. The vibrational and electronic spectra of peramine and some of its derivatives were recorded, and assignments were made on the basis of B3LYP/aug-cc-pVDZ level calculations; FTIR and ${ }^{1} \mathrm{H}$ NMR spectra indicated the conjugation of the pyrrolo and pyrazinone rings. These previous results also show that the ring modes are insensitive to the type of substituent introduced into the side chain of peramine.

We consider here a series of pyrrolopyrazinones (Scheme 1, Table 1) that is an extension of our previous work on $\mathrm{N}$ substituted 2-acylpyrroles [9]. For some of the heterocyclic systems analyzed recently, short $\mathrm{C}=\mathrm{O} \cdots \mathrm{H}-\mathrm{C}$ intramolecular contacts are observed [10]. This observation inspired us to undertake a theoretical study on $\mathrm{C}=\mathrm{O} \cdots \mathrm{H}-\mathrm{C}$ intramolecular hydrogen bonds in pyrrolopyrazinone species.

In the first part of this study, we carried out a detailed analysis of the geometrical parameters of the pyrrolopyrazinone derivatives (Scheme 1). These species are divided into two groups according to QTAIM results; one group includes systems with short $\mathrm{C}=\mathrm{O} \cdots \mathrm{H}-\mathrm{C}$ contacts in which $\mathrm{O} \cdots \mathrm{H}$ bond paths with corresponding BCPs exist (all pyrrolopyrazines where $\mathrm{R}_{2}=\mathrm{CHCl}_{2}$ are included here); the other group consists of systems in which there is no attractive $\mathrm{C}=\mathrm{O} \cdots \mathrm{H}-\mathrm{C}$ interaction and the $\mathrm{H}^{\cdots} \mathrm{O}$ bond paths are not detected; all systems where $\mathrm{R}_{2}=\mathrm{CH}_{2} \mathrm{Cl}$ are included in this group. There are also systems in which $\mathrm{R}_{2}=\mathrm{CH}_{3}$ are dispersed into both these groups. 


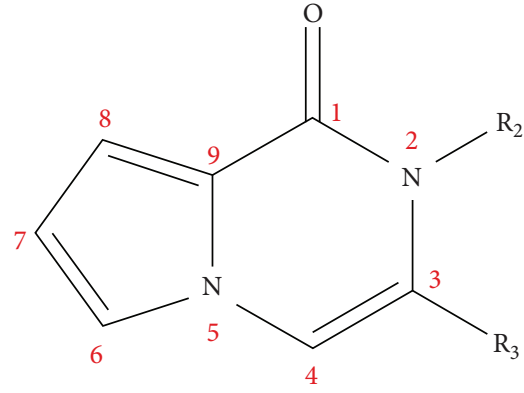

Scheme 1: Schematic representation of the structure and atom numbering of pyrrolopyrazinone derivatives (2-22) where $\mathrm{R}_{2}=\mathrm{CH}_{3}, \mathrm{CH}_{2} \mathrm{Cl}$, or $\mathrm{CHCl}_{2} ; \mathrm{R}_{3}=\mathrm{H}, \mathrm{Cl}, \mathrm{CH}_{3},\left(\mathrm{CH}_{2}\right)_{\mathrm{n}} \mathrm{CH}_{3}$, $\left(\mathrm{CH}_{2}\right)_{\mathrm{n}} \mathrm{CH}_{2} \mathrm{Cl},\left(\mathrm{CH}_{2}\right)_{\mathrm{n}} \mathrm{NH}_{2}, \mathrm{NH}_{2}$, and $\left(\mathrm{CH}_{2}\right)_{3} \mathrm{NHC}(\mathrm{NH}) \mathrm{NH}_{2}$.

In the second part of this study, analysis of the aromaticity of the pyrrolopyrazinone derivatives was carried out to find the possible interplay between the existence of the hydrogen bonds and aromaticity of the heterocyclic rings. Aromaticity is a topic of scientific interest in the various areas of pyrrole derivative investigation. Numerous aromaticity concepts have been proposed to describe and evaluate this phenomenon. Criteria for establishing aromaticity of various species analyzed have been divided $[10,11]$ into energetic, [12] geometrical, [13] magnetic [14], and reactivity categories; the latter ones are mainly based on the chemical behavior of a system. There is also the harmonic oscillator model of aromaticity (HOMA) [15-18] that is classified as a geometrical index.

In general, the purpose of this study is to extend knowledge of physicochemical properties of pyrrolopyrazinones including spectroscopic properties of both heterocyclic rings. Theoretical analysis is performed using B3LYP/aug-cc-pVDZ calculations, the quantum theory of atoms in molecules (QTAIM) approach, and the natural bond orbital (NBO) method. The intramolecular $\mathrm{C}=\mathrm{O} \cdots \mathrm{H}-\mathrm{C}$ hydrogen bonds in the pyrrolopyrazinone molecules (1-22) are analyzed in terms of the NBO method, and orbital-orbital overlapping energy, $\Delta \mathrm{E}_{\mathrm{n} \rightarrow \sigma *}$, is discussed [19]. To the best of our knowledge, NBO, QTAIM, or HOMA approaches have not been applied so far to analyze the intramolecular $\mathrm{C}=\mathrm{O} \cdots \mathrm{H}-\mathrm{C}$ interactions in pyrrolopyrazinones (2-22).

\section{Experimental FT-IR Spectra}

The infrared spectrum of peramine 20 was investigated at room temperature in $\mathrm{KBr}$ pellets containing dispersed compounds. The FT-IR absorption spectrum was recorded in the range between 400 and $4000 \mathrm{~cm}^{-1}$ with a Nicolet Magna-IR 550 Series II instrument.

\section{Computational Details}

The calculations were performed with the Gaussian 09 sets of codes [20]. The geometries of the investigated species (1-22) were fully optimized using the aug-cc-pVDZ Dunning's correlation consistent basis set $[21,22]$ and B3LYP functional $[23,24]$. Calculations of normal modes were performed with the use of the same level as that for the optimizations. The results of optimization correspond to energy minima since no imaginary frequencies were detected. The initial geometry of the pyrrolopyrazinone system was taken from X-ray data, and it was further applied in the geometry optimization [9]. The computed frequencies were multiplied by the uniform factor of 0.97 to obtain a good estimate of the experimental results and to eliminate known systematic errors related to anharmonicity [25].

Gaussian output wfn files were used as inputs for the AIM2000 [26] program to calculate topological properties of the systems investigated. The bond and ring critical points were located (BCPs and RCPs), and their properties, such as electron densities at critical points $\left(\rho_{\mathrm{BCP}}\right.$ and $\left.\rho_{\mathrm{RCP}}\right)$ and their Laplacians $\left(\nabla^{2} \rho_{\mathrm{BCP}}\right.$ and $\left.\nabla^{2} \rho_{\mathrm{RCP}}\right)$, were calculated. The additional characteristics of BCPs were analyzed, such as total electron energy density at $\mathrm{BCP}\left(\mathrm{H}_{\mathrm{BCP}}\right)$ and its components, potential electron energy density $\left(\mathrm{V}_{\mathrm{BCP}}\right)$, and kinetic electron energy density $\left(\mathrm{G}_{\mathrm{BCP}}\right)$.

Particularly, for the $\mathrm{C}-\mathrm{H}^{\cdots} \mathrm{O}$ hydrogen bond, these are the characteristics of the $\mathrm{H}^{\cdots \cdots} \mathrm{O}$ bond critical point and the properties of the ring critical point that exist within the ring closed by the $\mathrm{C}=\mathrm{O} \cdots \mathrm{H}-\mathrm{C}$ intramolecular hydrogen bond. Relationships between topological parameters at the critical point are given by [27]

$$
0.25 \nabla^{2} \rho_{\mathrm{BCP}}=2 \mathrm{G}_{\mathrm{BCP}}+\mathrm{V}_{\mathrm{BCP}} ; \mathrm{H}_{\mathrm{BCP}}=\mathrm{G}_{\mathrm{BCP}}+\mathrm{V}_{\mathrm{BCP}} .
$$

Kinetic electron energy density $G_{B C P}$ has a positive value, whereas potential electron energy density $V_{B C P}$ has a negative value. If the absolute value of $\mathrm{V}_{\mathrm{BCP}}$ is two times greater than the $G_{B C P}$ value, the Laplacian $\nabla^{2} \rho_{B C P}$ is negative. The classification of hydrogen bonds based on these parameters has been proposed by Rozas and coworkers [28]. $\nabla^{2} \rho_{\mathrm{BCP}}$ and $\mathrm{H}_{\mathrm{BCP}}$ values are positive for weak and medium-strength $\mathrm{HB}$ interactions; $\nabla^{2} \rho_{\mathrm{BCP}}$ is positive and $\mathrm{H}_{\mathrm{BCP}}$ is negative for strong hydrogen bonds; both these values are negative for very strong $\mathrm{HBs}$. The electron density at $\mathrm{H}^{\cdots} \mathrm{B} B \mathrm{BC}, \rho_{\mathrm{BCP}}$, is often considered as a measure of $\mathrm{A}-\mathrm{H}^{\cdots} \mathrm{B}$ hydrogen bond strength since correlations between $\rho_{\mathrm{BCP}}$ and interaction energy or other HB strength descriptors have been found, especially for homogenous samples of interactions [29]. Similarly, in this study, $\rho_{\mathrm{BCP}}$ that corresponds to the $\mathrm{H}^{\cdots} \mathrm{O} \mathrm{BCP}$ of the $\mathrm{C}-\mathrm{H}^{\cdots} \mathrm{O}$ intramolecular hydrogen bond may be considered a descriptor of $\mathrm{HB}$ strength.

The NBO method [19] was applied to calculate $n_{B} \rightarrow \sigma^{*}{ }_{A H}$ interaction energies. $n_{B}$ designates the lone pair of the $\mathrm{B}$ proton acceptor, and $\sigma^{*}{ }_{A-H}$ is an antibonding orbital of the A-H bond. Interaction energy was calculated from second-order perturbation theory energy according to

$$
E_{A B}^{(2)}=-n_{Y} \frac{F_{\sigma_{A H}^{*}}^{2}}{\varepsilon_{\sigma_{A H}^{*}}-\varepsilon_{n_{B}}},
$$

where $F_{\sigma_{A H}^{*}}^{2}$ is the Fock matrix element, $\varepsilon_{\sigma_{A H}^{*}}-\varepsilon_{n_{B}}$ is the orbital energy difference, and $n_{B}$ is the population of the donor $B$ orbital. The $\mathrm{E}^{(2)}{ }_{\mathrm{AB}}$ energy term can be considered a part of charge transfer energy or stabilization energy associated with delocalization. 


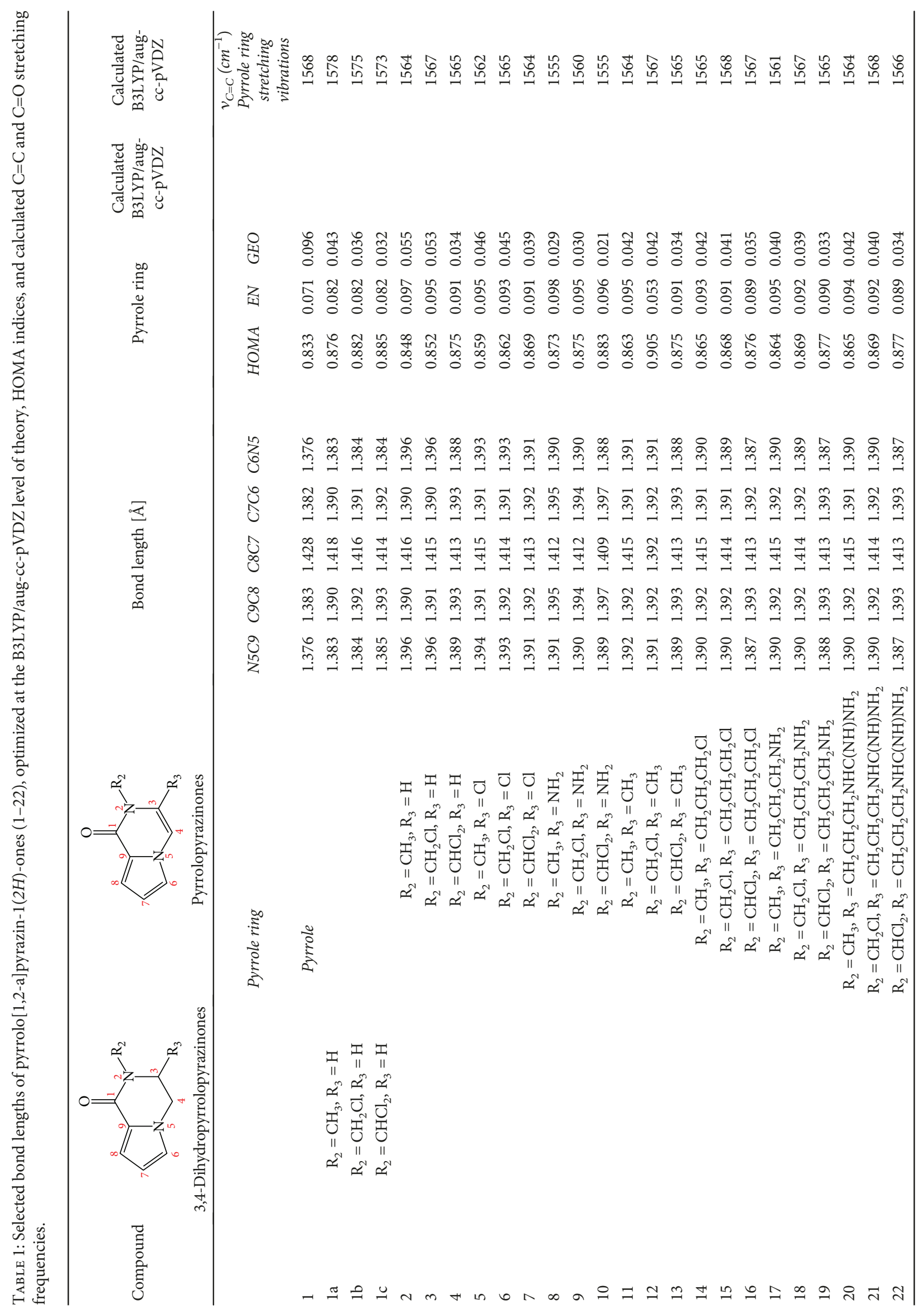




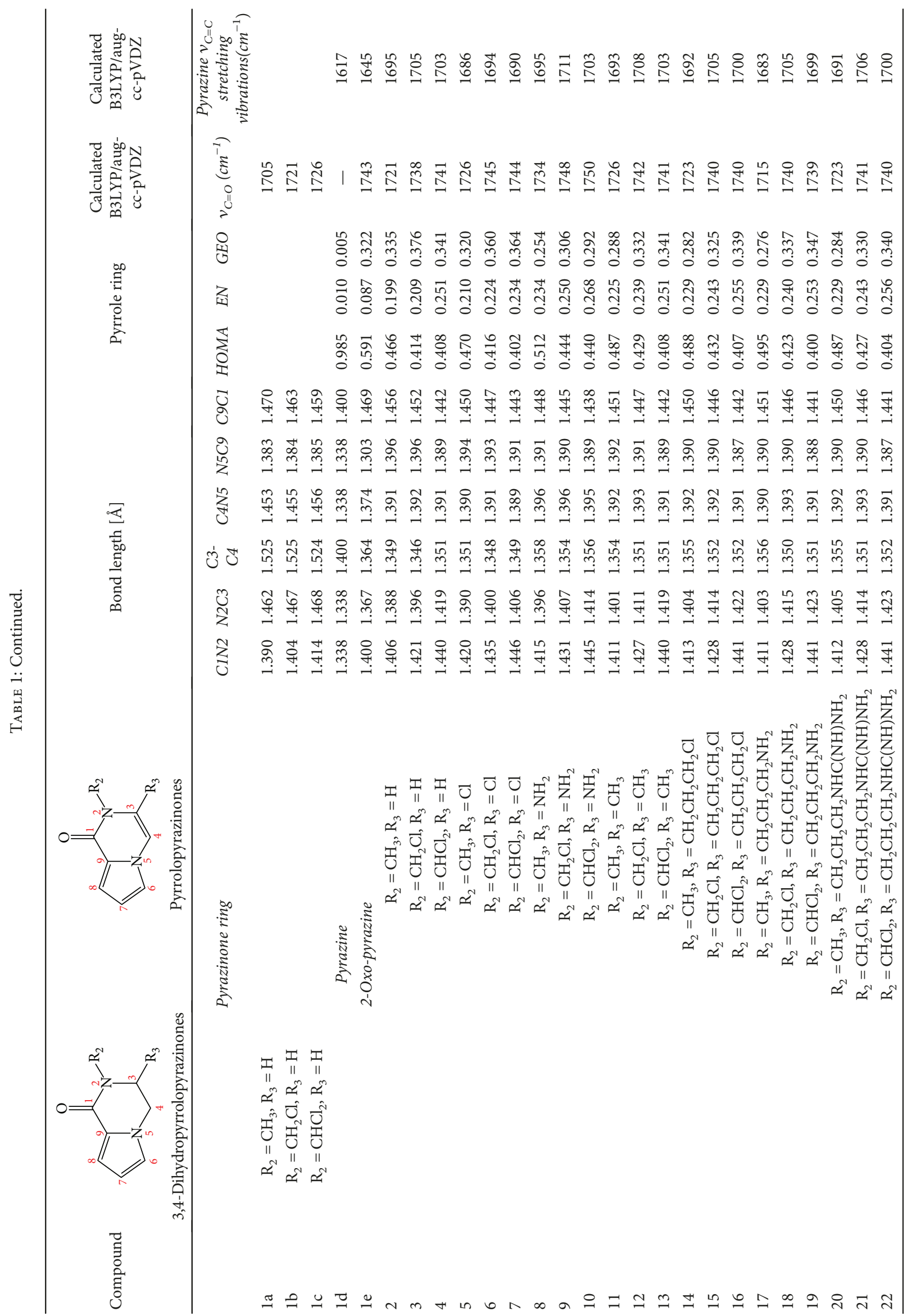


The HOMA index is expressed by

$$
\text { HOMA }=1-\frac{\alpha}{n} \sum\left(R_{\text {opt }}-R_{i}\right)^{2},
$$

where $n$ is the number of bonds taken into account, $\alpha$ is an empirical constant chosen to give HOMA $=0$ for a nonaromatic system and HOMA $=1$ for a system with all bonds equal to the optimal value $R_{o p t}$, and $R_{i}$ is the individual bond length [30]. The HOMA index has a value between 1 for entirely aromatic molecules and 0 for nonaromatic systems. When the value of the HOMA index is less than zero, the structure is antiaromatic.

The Pauling bond number and virtual $\mathrm{CC}$ and $\mathrm{CN}$ bond lengths have been applied to the HOMA aromaticity index. This allows separation of HOMA into energetic and geometric contributions for heterocyclic $\pi$-electron systems [29]. The expression for the HOMA term is as follows:

$$
\mathrm{HOMA}=1-\left[257.7\left(1.388-R_{a v}\right)^{2}+\frac{257.7}{N} \sum\left(R_{a v}-R_{i}\right)^{2}\right],
$$

where $N$ is the number of bonds taken into calculation, $R_{a v}$ is the averaged bond length, $R_{a v}=1 / n \sum_{i=1}^{n} R_{i}$, and $R_{i}$ is the virtual bond length calculated from the Pauling bond number [29] $n_{i}=\exp (R(1)-R(n) / c)$.

According to the general formula,

$$
R_{n}=1.467-0.1702 \ln (n) .
$$

\section{Results and Discussion}

4.1. Geometry of the $C-H^{\cdots} \mathrm{O}=\mathrm{C}$ Intramolecular Contact. Scheme 1 presents pyrrolopyrazinone systems analyzed here, $2-22$. Pyrrole, 1, and pyrazine, $1 \mathrm{~d}, 1 \mathrm{a}-\mathrm{c}$, and 1e, which may be treated as fragments of these systems, are also analyzed for comparison. Selected geometrical parameters for all these species (1-22) are listed in Table 1. Three sets of samples of pyrrolopyrazinone systems which differ in the $\mathrm{R}_{2}$ substituent may be selected here; the sample where $\mathrm{R}_{2}=\mathrm{CH}_{3}(2,5,8,11$, 14,17 , and 20), $\mathrm{R}_{2}=\mathrm{CH}_{2} \mathrm{Cl}(3,6,9,12,15,18$, and 21), and the sample where $\mathrm{R}_{2}=\mathrm{CHCl}_{2}(4,7,10,13,16,19$, and 22).

For some of the systems analyzed, the existence of C$\mathrm{H}^{\cdots} \mathrm{O}$ intramolecular hydrogen bonds is observed which close additional five-membered rings. We can expect here weak hydrogen bonds which are formed when the hydrogen atom is covalently bonded to a slightly more electronegative atom relative to hydrogen; the electronegativity of carbon of 2.55 is only slightly higher than that of hydrogen, that is, 2.20 , according to the Pauling electronegativity scale. The identification of the $\mathrm{A}-\mathrm{H}^{\cdots} \mathrm{B}$ hydrogen bond is often based on the $\mathrm{A} \cdots \mathrm{B}$ distance which should be lower than the sum of their van der Waals radii; this criterion can be applied for strong and medium strength interactions. It is inadequate for weaker hydrogen bonds that are mainly electrostatic in nature. This is why the criterion of the sum of van der Waals radii is more often applied for the $\mathrm{H}^{\cdots} \mathrm{B}$ distances; however, it is also sometimes not fulfilled for weaker interactions. The most probable interpretation is that for weak hydrogen bonds the long-range electrostatic forces act far beyond the van der Waals radii cutoff $[31,32]$ while for strong and very strong interactions the additional forces related to electron density shifts are more important; these forces lead to the enormous shortening of the H...B hydrogen bond contact [31]. The role of electrostatic forces in hydrogen bonds and in other interactions, such as for example, halogen bonds, is in line with the $\sigma$-hole concept [33].

Table 2 presents the geometrical parameters corresponding to the $\mathrm{C}-\mathrm{H}^{\cdots}{ }^{\cdots} \mathrm{O}=\mathrm{C}$ hydrogen bonds, $\mathrm{H}^{\cdots} \mathrm{O}$ distances, $\mathrm{d}_{\mathrm{HO}}$ 's and $\angle \mathrm{C}-\mathrm{H}^{\cdots} \mathrm{O}$ angles. We can observe that among the $\mathrm{C}$ $\mathrm{H}{ }^{\cdots} \mathrm{O}=\mathrm{C}$ contacts there are systems with short $\mathrm{H}^{\cdots \cdots} \mathrm{O}$ distances below the sum of vdW radii- $2.72 \AA(\mathrm{O}, 1.52 \AA$ and $\mathrm{H}, 1.20 \AA$ ), according to Bondi $[34,35]$. One of the most important geometrical characteristics of hydrogen bonds is that the distance between the proton and the protonaccepting atom is shorter than the sum of their van der Waals radii. Additional generally accepted criterion is that the donor-proton-acceptor angle in hydrogen bond must be at least $90^{\circ}$ [36]. For $3,6,9,12,15,18$, and 21, in which $\mathrm{R}_{2}=\mathrm{CH}_{2} \mathrm{Cl}$, the $\mathrm{H} \cdots \mathrm{O}$ distance varies from 2.19 to $2.27 \AA$. Systems $2,5,8,11,14,17$, and 20 , where $\mathrm{R}_{2}$ is a methyl group $\left(\mathrm{CH}_{3}\right)$, are characterized by the $\mathrm{H}^{\cdots} \mathrm{O}$ distance range of $2.17-2.24 \AA$ and the $\angle \mathrm{C}-\mathrm{H}$...O angle range of $106-118^{\circ}$ (Table 2). The systems with the $\mathrm{R}_{2}=\mathrm{CHCl}_{2}$ group $(4,7,10$, $13,16,19$, and 22) are characterized by the shortest $\mathrm{H}^{\cdots} \mathrm{O}$ distances of 2.03-2.06 $\AA$, much shorter than the sum of vdW radii of $\mathrm{H}$ and $\mathrm{O}$ atoms $(2.68 \AA)$; the $\angle \mathrm{C}-\mathrm{H}$... O angle range of $111-113^{\circ}$ is observed here (Table 2). It is noted that the above values are within the range acceptable for intramolecular $\mathrm{H}$-bonds since the accepted $\mathrm{H}^{\cdots} \mathrm{O}$ distance range for the $\mathrm{C}-\mathrm{H}^{\cdots} \mathrm{O}$ hydrogen bonds is $2.0-2.7 \AA$ [36]. Recent studies have also suggested the $\mathrm{C}-\mathrm{H}^{\cdots} \mathrm{X}$ angles up to $90^{\circ}$ for acceptable hydrogen bonds [37].

The phenomenon which influences the geometry of C$\mathrm{H}^{\cdots} \mathrm{O}=\mathrm{C}$ interactions is the acidity of the proton donating $\mathrm{C}-\mathrm{H}$ group [38]. The main factor that controls both lengths and energies is the acidity of the $\mathrm{C}-\mathrm{H}$ group. The acidity of the $\mathrm{C}-\mathrm{H}$ group can sweep over a wide range of $\mathrm{pKa}$ values prompted by changes of the hybridization state of the carbon and for effect of electron-withdrawing substituents. The acidity of the $\mathrm{C}-\mathrm{H}$ bond is increasing in the following order: $\mathrm{sp}^{3} \mathrm{C}-\mathrm{H}, \mathrm{sp}^{2} \mathrm{C}-\mathrm{H}$, and $\mathrm{spC}-\mathrm{H}$. For instance, $\mathrm{pKa}$ in water of $\mathrm{CH}_{4}, \mathrm{C}_{2} \mathrm{H}_{4}$, and $\mathrm{C}_{2} \mathrm{H}_{2}$ decreases in the order 48 , 44 , and 26. The effects of the $\mathrm{C}-\mathrm{H}$ acidity on the geometry of the $\mathrm{C}-\mathrm{H}^{\cdots} \mathrm{O}$ bonds have been studied by Desiraju [38]. It was found that $\mathrm{C} \cdots \mathrm{O}$ contact distances correlate with pKa values. Shorter bonds are associated with the more acidic C-H group [39, 40].

Replacement of the $\mathrm{H}$ atom from the group $\mathrm{R}_{2}=\mathrm{CH}_{3}$ by $\mathrm{Cl}$ results in a reduction in the $\mathrm{H}^{\cdots} \mathrm{O}$ distance [9]. This is also observed for the systems analyzed here; for example, the $\mathrm{H}^{\cdots} \mathrm{O}$ distance is equal to $2.17,2.03 \AA$ for $20\left(\mathrm{R}_{2}=\mathrm{CH}_{3}\right)$ and $22\left(\mathrm{R}_{2}=\mathrm{CHCl}_{2}\right)$, respectively (Table 2$)$; it means that shorter $\mathrm{H}^{\cdots} \mathrm{O}$ distances occur for more acidic $\mathrm{C}-\mathrm{H}$ donors. The $\mathrm{C}$ $\mathrm{H}^{\cdots} \mathrm{O}$ angle varies from $102.8^{\circ}$ in $12\left(\mathrm{R}_{2}=\mathrm{CH}_{2} \mathrm{Cl}\right)$ to 104.91 in $21\left(\mathrm{R}_{2}=\mathrm{CH}_{2} \mathrm{Cl}\right)$. For systems with $\mathrm{R}_{2}=\mathrm{CH}_{3}$, the $\mathrm{C}-\mathrm{H}^{\cdots} \mathrm{O}$ angle varies from $106.1^{\circ}$ in 2 to 112.42 in 22 . For systems with $\mathrm{R}_{2}=\mathrm{CHCl}_{2}$, the $\mathrm{C}-\mathrm{H}^{\cdots} \mathrm{O}$ angle varies from $107.67^{\circ}$ in 4 to 


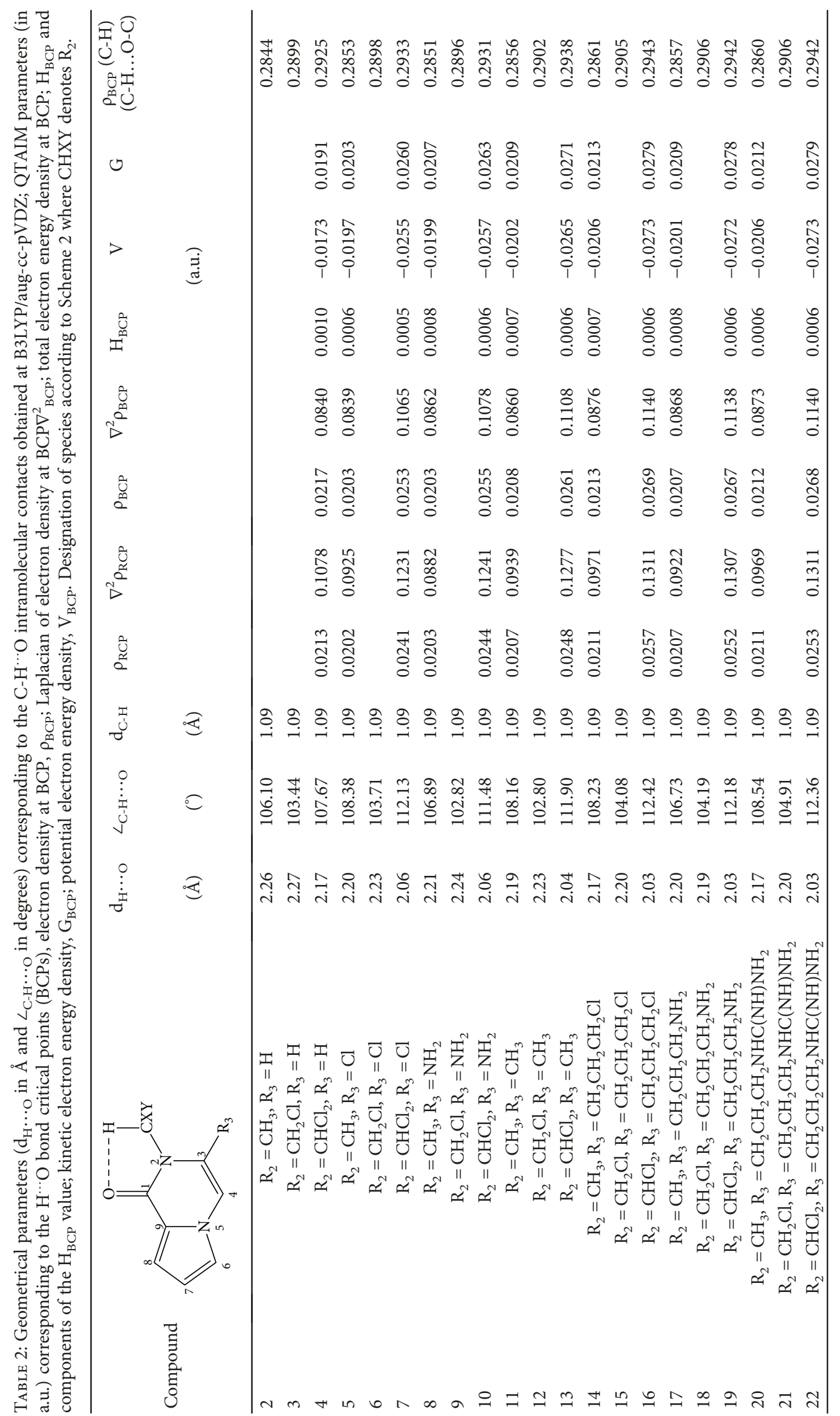




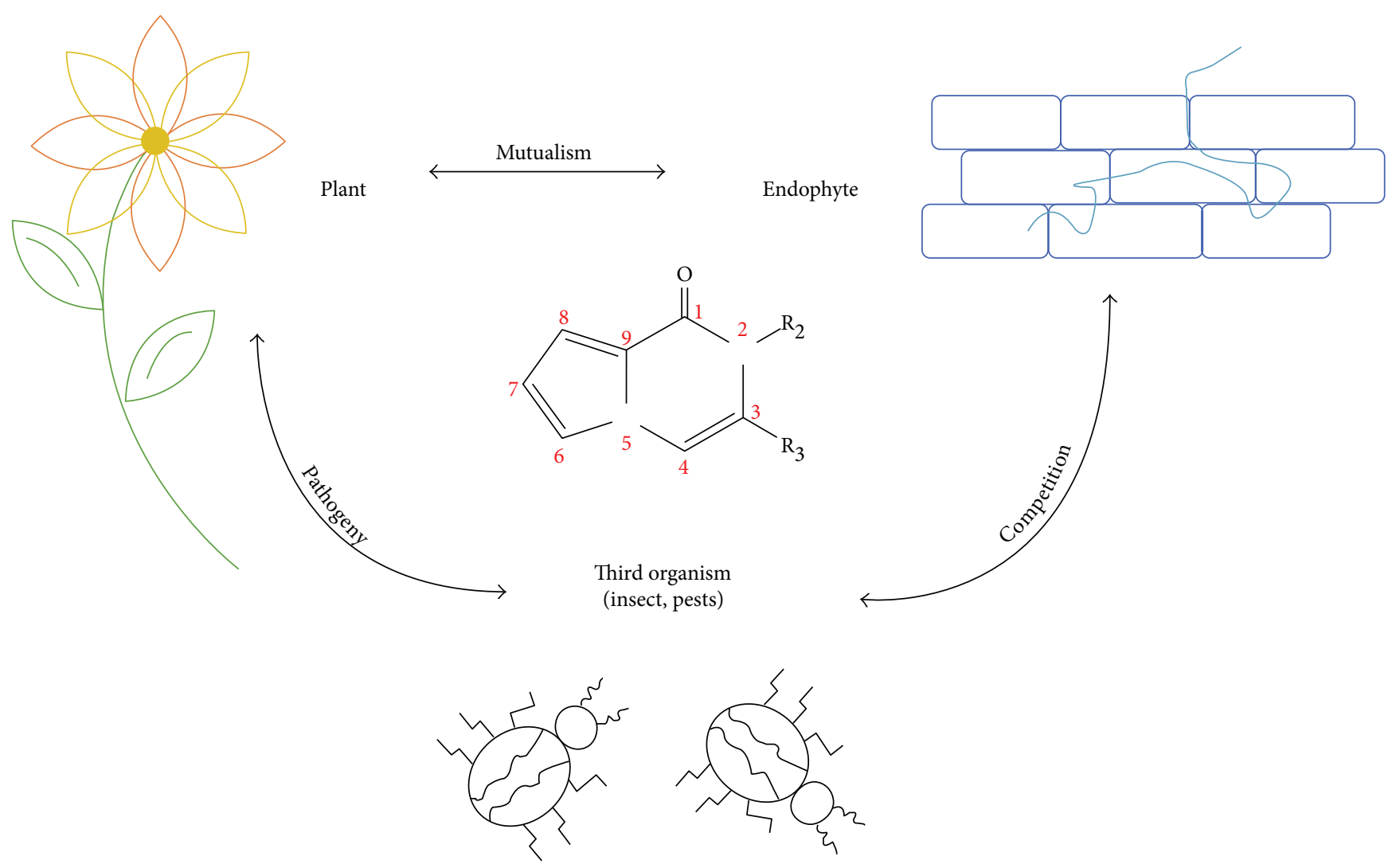

Scheme 2: Schematic representation of the endophyte-infected plant.

108.54 in 20. It means that electron-withdrawing substituents affect $\mathrm{CH}^{\cdots} \mathrm{O}$ bond geometry. It is observed that the introduction of two chlorine atoms where $\mathrm{R}_{2}=\mathrm{CHCl}_{2}(4,7,10,13,16$, 19 , and 22) led to an increase of the $\mathrm{C}-\mathrm{H}^{\cdots} \mathrm{O}$ angle in comparison with molecules where $\mathrm{R}_{2}=\mathrm{CH}_{3}$ as well as $\mathrm{R}_{2}=\mathrm{CH}_{2} \mathrm{Cl}$. It is interesting to compare the $\mathrm{C}-\mathrm{H}^{\cdots} \mathrm{O}$ angle of systems where $\mathrm{R}_{2}=\mathrm{CH}_{3}$ and the $\mathrm{C}-\mathrm{H}^{\cdots} \mathrm{O}$ angle of systems where $\mathrm{R}_{2}=\mathrm{CH}_{2} \mathrm{Cl}$. Bond angle $\angle \mathrm{C}-\mathrm{H}$... O values for a system where $\mathrm{R}_{2}=\mathrm{CH}_{3}$ are larger than $\angle \mathrm{C}-\mathrm{H} \ldots \mathrm{O}$ for a system where $\mathrm{R}_{2}=\mathrm{CH}_{2} \mathrm{Cl}$.

For all molecules, under consideration $(2-22)$, the $\mathrm{H}^{\cdots} \mathrm{O}$ distances are within the range acceptable for intramolecular $\mathrm{H}$-bonds. To find whether these $\mathrm{H}^{\cdots} \mathrm{O}$ contacts may be classified as attractive hydrogen bonds, additional QTAIM and NBO analyses were performed here.

4.2. QTAIM Analysis. The quantum theory of atoms in molecules, QTAIM [27], is often applied to analyze different inter- and intramolecular interactions, such as $\mathrm{A}-\mathrm{H}^{\cdots} \mathrm{B}$ hydrogen bonds [41]. The existence of the $\mathrm{H}^{\cdots} \mathrm{B}$ bond path as well as the characteristics of the corresponding bond critical point such as electron density, $\rho_{\mathrm{BCP}}$, and its Laplacian, $\nabla^{2} \rho_{\mathrm{BCP}}$, is often used as criteria for the existence of the hydrogen bond [42]. That is why QTAIM analysis was also performed here for pyrrolopyrazinones (2-22). Figure 1 presents molecular graphs of peramine derivatives $21(\mathrm{X}=\mathrm{H}$, $\mathrm{Y}=\mathrm{Cl})$ and $22(\mathrm{X}=\mathrm{Cl}, \mathrm{Y}=\mathrm{Cl})$ which are analyzed in this study; these are two examples of systems where the QTAIM approach confirms the existence of $\mathrm{HB}$ (22), or it does not confirm such interaction since the $\mathrm{H}^{\cdots} \mathrm{O}$ intramolecular bond path was not detected (21). Based on QTAIM, there are no bond paths connecting the oxygen atom and the methylene hydrogen atom for $2,3,6,9,12,15,18$, and 21 , that is, for all systems where $\mathrm{R}_{2}=\mathrm{CH}_{2} \mathrm{Cl}$ and for certain systems where $\mathrm{R}_{2}=\mathrm{CH}_{3}$ (Scheme 1). The $\mathrm{H}$ atom $=\mathrm{CH}_{3}$ is located at $2.6 \AA$ distance from the hydrogen atom of the $\mathrm{R}_{3}$ group and has no steric repulsion between the $R_{2}$ and $R_{3}$ electron clouds. This effect leads to the lack of attractive interaction of $\mathrm{HB}$ between the carbonyl group and the neighboring $\mathrm{CH}_{3}$ group [9].

There is a bond path connecting $\mathrm{C}=\mathrm{O}$ and $\mathrm{C}-\mathrm{H}$ groups for systems $4,7,10,13,16,19,22$, that is, for structures where $\mathrm{R}_{2}=\mathrm{CHCl}_{2}(\mathrm{X}=\mathrm{Cl}, \mathrm{Y}=\mathrm{Cl}$ according to Table 2$)$ and where the $\mathrm{H}^{\cdots} \mathrm{O}$ distance is much shorter than the corresponding sum of the vdW radii (see the discussion in the previous section). There is also a subset of the group in which $\mathrm{R}_{2}=\mathrm{CH}_{3}(5,8,11$, 14,17 , and 20) where a bond path exists connecting the oxygen atom of the carbonyl group and the hydrogen atom of the $\mathrm{CH}_{3}$ group (Table 2).

Table 2 presents selected QTAIM parameters for the systems analyzed here, that is, characteristics of the $\mathrm{H}^{\cdots} \mathrm{O}$ BCP corresponding to the intramolecular hydrogen bond: electron density at the bond critical point, $\rho_{\mathrm{BCP}}$, its Laplacian, $\nabla^{2} \rho_{\mathrm{BCP}}$, and the energetic BCP characteristics $\left(\mathrm{H}_{\mathrm{BCP}}, \mathrm{V}_{\mathrm{BCP}}\right.$, and $\mathrm{G}_{\mathrm{BCP}}$ ), as well as the properties of the ring critical point corresponding to the ring closed by this hydrogen bond: electron density at the ring critical point, $\rho_{\mathrm{RCP}}$, and its Laplacian, $\nabla^{2} \rho_{\mathrm{RCP}}$. The typical topological parameters at the bond critical point for the hydrogen bond are $0.002-0.34$ a.u. for 


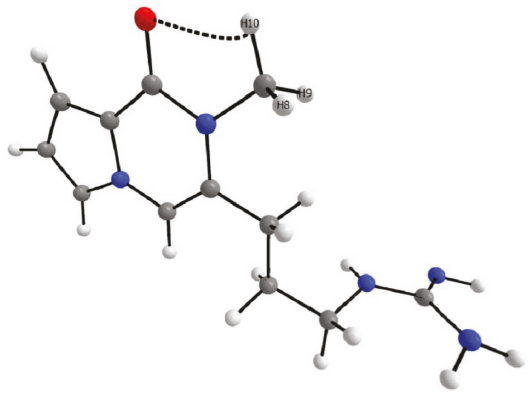

(a)

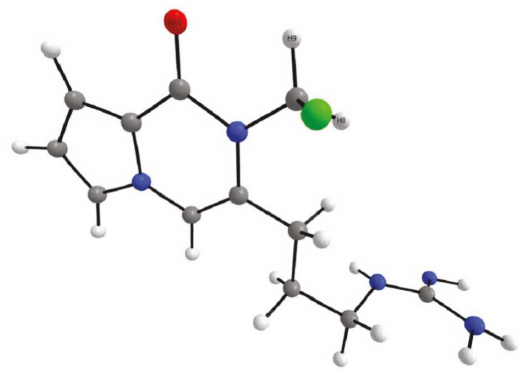

(b)

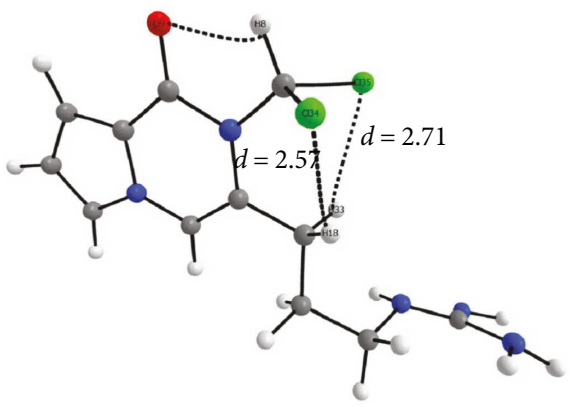

(c)

FIGURE 1: Molecular graphs (representation of bonding interactions according to QTAIM results) of the system analyzed in this study: 23 (a), 22 (b), and 21 (c). The dotted line corresponds to a bond path.

electron density and 0.02-0.139 a.u. for its Laplacian [27]. The QTAIM analysis of electron densities at the $\mathrm{H}^{\cdots} \mathrm{O}$ bond critical points of the systems under consideration (2-22) showed that $\rho_{\mathrm{BCP}}$ is in a range of 0.0269 to 0.0203 a.u., and Laplacian varies from 0.0839 to 0.114 a.u. It has been shown earlier that electron density and its Laplacian correlate with $\mathrm{H}$-bond energy, especially for homogeneous samples of interactions [31, 40, 43]. The increase of $\mathrm{HB}$ strength is related to the increase of electron density at the BCP.

The largest electron density at the proton-acceptor $(\mathrm{H} \cdots \mathrm{O})$ bond critical point is observed for $16\left(\mathrm{R}_{2}=\mathrm{CHCl}_{2}\right.$, $\left.\mathrm{R}_{3}=\left(\mathrm{CH}_{2}\right)_{3} \mathrm{Cl}\right)$, peramine derivative $19\left(\mathrm{R}_{2}=\mathrm{CHCl}_{2}, \mathrm{R}_{3}=\right.$ $\left.\left(\mathrm{CH}_{2}\right)_{3} \mathrm{NH}_{2}\right)$, and $22\left(\mathrm{R}_{2}=\mathrm{CHCl}_{2}, \mathrm{R}_{3}=\left(\mathrm{CH}_{2}\right)_{3} \mathrm{NHC}(\mathrm{NH})\right.$ $\mathrm{NH}_{2}$ ), $0.0269,0.0267$, and 0.0268 a.u., respectively.

Figure $1(\mathrm{c})$ presents a molecular graph of system 22 where $\mathrm{R}_{2}=\mathrm{CHCl}_{2}$. In this structure, shown in Figure $1(\mathrm{c})$, there is a bond path connecting oxygen atom and $\mathrm{H} 8$ atom of the $\mathrm{R}_{2}$ group. There is also a bond path connecting atom $\mathrm{Cl} 34$ and atom $\mathrm{H} 18$ of methylene group as well as atom $\mathrm{Cl} 35$ and atom $\mathrm{H} 33$. The $\mathrm{Cl} 34$...H18 distance is $2.57 \AA$; the Cl34..H33 distance is $2.71 \AA$. We believe that carbon atom of the proton donor group $\left(\mathrm{R}_{2}=\mathrm{CHCl}_{2}\right)$ carries a more positive charge than the carbon atom of the $\mathrm{CH}_{2} \mathrm{Cl}$ group. Furthermore, for these systems, the $\angle \mathrm{C}-\mathrm{H}$... O bond angle is closest to $120^{\circ}$ compared with that of the other species $\left(\mathrm{R}_{2}=\mathrm{CH}_{2} \mathrm{Cl}\right)$ in Table 2 and Figures $1(\mathrm{a})$ and $1(\mathrm{c})$. In such a case, the proton of $R_{2}$ group is located in the chelate ring plane. In spite of this results obtained, it seems that the path linking both $\mathrm{C}=\mathrm{O} \ldots \mathrm{H}-\mathrm{C}$ is an attractive interaction.

For the sample 21 where $\mathrm{R}_{2}=\mathrm{CH}_{2} \mathrm{Cl}$, the $\mathrm{Cl} \ldots \mathrm{H}$ distance is $2.81 \AA$, and the $\angle \mathrm{C}-\mathrm{H}$... O bond angle is $104.91^{\circ}$. In such a case, there is not a bond path connecting carbonyl oxygen with hydrogen of the R2 group (Figure 1(b)). This may be explained because of minimal $n_{B} \rightarrow \sigma_{A H}^{*}$ overlap [44]. Hence, if hydrogen bonding is stronger, thus the $\mathrm{C}-\mathrm{H}^{\cdots} \mathrm{O}$ angle is closer to $120^{\circ}$.

It is seen that systems with $\mathrm{R}_{2}=\mathrm{CHCl}_{2}$ correspond to the strongest interactions since it is also supported by other results collected in Table 2 that the shortest $\mathrm{H}^{\cdots} \mathrm{O}$ distances are observed for the systems mentioned above. It is in agreement with the properties of the $\mathrm{Cl}$ atom as an electronwithdrawing substituent that enhances the proton-donating ability of the adjacent $\mathrm{CH}$ group. The latter was suggested in a previous study [45] that the strength of the $\mathrm{C}-\mathrm{H}^{\cdots} \mathrm{B}$ hydrogen bond strongly depends on the nature of the proton donor and increases when hydrogen atoms are replaced by electron-withdrawing substituents $[9,46]$.

The correlation between the length of the hydrogen bond and electron density at the corresponding bond critical point, $\rho_{\mathrm{BCP}}$, which is often analyzed for samples of related species, is also observed here (Figure 2). Pyrrolopyrazinones analyzed here, where the $\mathrm{H}^{\cdots} \mathrm{O}$ bond path corresponding to the intramolecular hydrogen bond was detected, can be divided into two groups (Figure 2); the group where $\mathrm{R}_{2}=\mathrm{CHCl}_{2}$ and the group where $\mathrm{R}_{2}=\mathrm{CH}_{3}$. For the first group, stronger interactions characterized by shorter $\mathrm{H}^{\cdots} \mathrm{O}$ distances and greater $\rho_{\mathrm{BCP}}$ values are observed than those for the second group (Figure 2).

The properties of the ring critical point which is observed for the intramolecular hydrogen bonds often correlate with other measures of $\mathrm{HB}$ strength. It is noted that for the HBs analyzed here there is a linear correlation between the $\rho_{\mathrm{BCP}}$ and $\rho_{\mathrm{RCP}}$ values $\left(\mathrm{R}^{2}=0.998\right)$. The $\mathrm{H}_{\mathrm{BCP}}$ value is also useful to describe properties of hydrogen bonds. It is 


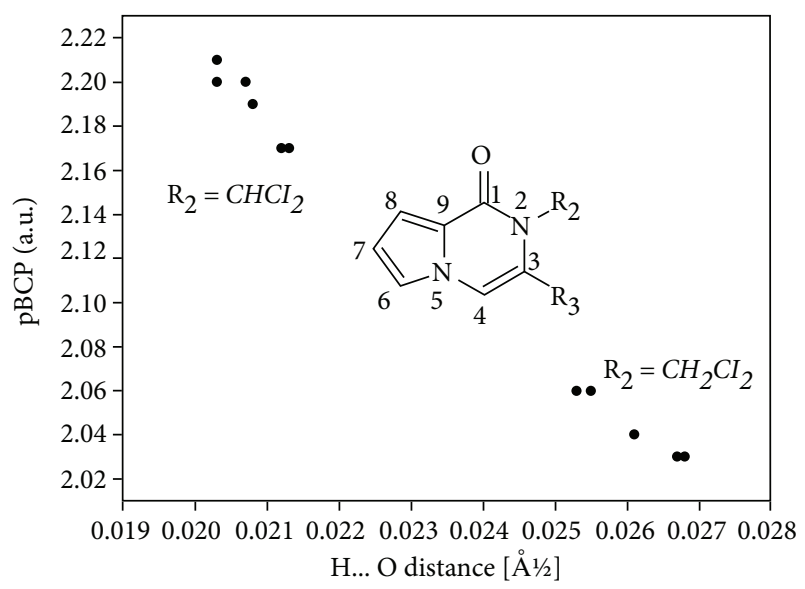

Figure 2: Correlation between electron density at the H-bond critical points $\rho_{\mathrm{BCP}}$ (in a.u.) and the $\mathrm{H}^{\cdots} \mathrm{O}$ distance (in $\AA$ ) was calculated at the B3LYP/aug-cc-pVDZ level. (4, 7, 10, 13, 16, 19, and 22; $\left.\mathrm{R}_{2}=\mathrm{CHCl}_{2}\right)\left(5,8,11,14,17\right.$, and 20; $\left.\mathrm{R}_{2}=\mathrm{CH}_{3}\right)$.

negative for interactions which are at least partly covalent in nature; for the systems analyzed here, it is positive and equal to $\sim 0.001$ a.u.

According to the latest studies on $\mathrm{HB}$ description, $\mathrm{HB}$ strength is related to the kinetic energy of electron density at the $\mathrm{BCP}$ and the decrease of potential energy and decrease of total electron energy density at the BCP [29]. G, V, and $\mathrm{H}_{\mathrm{BCP}}$ are the kinetic, potential, and total electron energy densities at critical point, respectively. $G$ is a positive value, whereas $\mathrm{V}$ is a negative one. Rozas et al. have classified $\mathrm{HB}$ based on Laplacian of electron density at BCP and HBCP values [28]. Medium and week in strength $\mathrm{HBs}$ show positive value of Laplacian of electron density at $\mathrm{BCP}$ as well as $\mathrm{H}$ value. It is seen that for systems analyzed here, $\nabla^{2} \rho_{\mathrm{BCP}}$ is positive, which means that HBs could be classified as weak. For the highest $\nabla^{2} \rho_{\mathrm{BCP}}$ value of $0.1140, \mathrm{H}_{\mathrm{BCP}}$ is 0.0006 , while $\mathrm{V}$ is -0.0273 . For the lowest $\nabla^{2} \rho_{\mathrm{BCP}}$ value of $0.0839, \mathrm{H}_{\mathrm{BCP}}$ is 0.0006 , while $\mathrm{V}$ is -0.0197 .

4.3. NBO Analysis. The NBO method is a useful tool to analyze intra- and intermolecular interactions. There are two effects that are often attributed to $\mathrm{A}-\mathrm{H} \cdots \mathrm{B}$ hydrogen bond formation: a hyper conjugative effect of $\mathrm{A}-\mathrm{H}$ bond weakening and rehybridization-promoted $\mathrm{A}-\mathrm{H}$ bond strengthening [47]. The hyper conjugative effect is related to electron charge transfer from the lone pair at the donor (B) into the antibonding $\sigma^{*}$ orbital of the A-H bond. The interaction between these orbitals corresponds to the deviation of the molecule from the Lewis structure [48]. The $\mathrm{E}_{\mathrm{AB}}{ }^{(2)}$ energy term mentioned earlier can be considered a part of charge transfer energy or the stabilization energy associated with the delocalization [49].

In NBO theory, a donor-acceptor picture of $\mathrm{H}$-bonding is based on overlap-type ionic resonance. The resonance hybrid $\mathrm{O} \ldots \mathrm{H}-\mathrm{C} \leftrightarrow \mathrm{OH}^{+} \ldots \mathrm{C}^{-}$corresponds to a two-electron intermolecular donor-acceptor interaction of the form $\mathrm{n}_{\mathrm{O}} \rightarrow \sigma^{*}{ }_{\mathrm{C}-\mathrm{H}}$ in which electron density from the lone pair $n_{O}$ of Lewis base (oxygen atom) delocalizes into the unfilled $\sigma^{*}{ }_{\mathrm{C}-\mathrm{H}}$ hydride antibonding orbital of the Lewis acid $(\mathrm{C}-\mathrm{H})$ [44]. Such intermolecular delocalization corresponds to partial charge transfer from the Lewis base to the Lewis acid. The larger the $\mathrm{E}^{(2)}$ value, the more intensive is the interaction between the donor and electron acceptor and the greater the extent of conjugation of the systems.

Table 3 presents NBO parameters for the molecules considered in this study. The charge transfer energy contribution denoted by $\mathrm{E}_{\mathrm{AB}}{ }^{(2)}$ that derives from the $\mathrm{n}_{\mathrm{O}} \rightarrow \sigma^{*}{ }_{\mathrm{C}-\mathrm{H}}$ orbitalorbital interaction is included. This energy ranges from $1.19 \mathrm{kcal} / \mathrm{mol}$ in system 12 to $2.87 \mathrm{kcal} / \mathrm{mol}$ in system 4 . Table 3 indicates that the interaction energy $\mathrm{E}^{(2)}$ between the lone pair of oxygen atom $\mathrm{LP}(2) \mathrm{O}-\sigma^{*}{ }_{\mathrm{C}-\mathrm{H}}$ for $4\left(\mathrm{R}_{2}=\mathrm{CHCl}_{2}\right)$ and $2\left(\mathrm{R}_{2}=\mathrm{CH}_{3}\right)$ is 2.87 and $1.32 \mathrm{kcal} / \mathrm{mol}$, respectively. Similarly, the interaction energy $\mathrm{E}^{(2)}$ between the lone pair of oxygen atom $\mathrm{LP}(2) \mathrm{O}-\sigma^{*}{ }_{\mathrm{C}-\mathrm{H}}$ for $22\left(\mathrm{R}_{2}=\mathrm{CHCl}_{2}\right)$ and $20\left(\mathrm{R}_{2}=\mathrm{CH}_{3}\right)$ is 1.95 and $1.83 \mathrm{kcal} / \mathrm{mol}$, respectively.

The s-character for the Lewis acid C-H increases in the order $\mathrm{R}_{2}=\mathrm{CH}_{3}, \mathrm{R}_{2}=\mathrm{CH}_{2} \mathrm{Cl}, \mathrm{R}_{2}=\mathrm{CHCl}_{2}$. For example, for 2,3 , and $4, \mathrm{C}-\mathrm{H}$ acceptor occupancy is equal to 0.0094 , 0.0178 , and 0.0317 , respectively. This effect was observed previously for the hydrogen bonding complexes [50]. The increase of s-character is accompanied by the increase of polarization of the $\mathrm{C}-\mathrm{H}$ bond. The electron density at the C-H BCP in $\mathrm{R}_{2}=\mathrm{CH}_{3}$ is lower than the electron density at $\mathrm{C}-\mathrm{H} \mathrm{BCP}$ in $\mathrm{R}_{2}=\mathrm{CHCl}_{2}$ (Table 2).

NBO results enable us to suggest the presence of an attractive $\mathrm{C}=\mathrm{O} \cdots \mathrm{H}-\mathrm{C}$ intramolecular interactions for all compound under study. Contrary to expectations, there is no QTAIM evidence of the existence of the hydrogen bond, 3, $6,9,12$, and 15 (where $\mathrm{R}_{2}=\mathrm{CH}_{2} \mathrm{Cl}$ ), since the $\mathrm{H}^{\cdots} \mathrm{O}$ bond path is not observed.

There was a similar earlier finding for the intramolecular dihydrogen bonds where for some systems the NBO method showed an orbital-orbital overlap typical for the intramolecular interaction while QTAIM did not show the corresponding bond path [51].

It is noted that the results presented here are partly consistent with AIM analysis. The greatest values of electron density at the $\mathrm{H}^{\cdots} \mathrm{O}$ bond critical point are observed for moieties where $\mathrm{R}_{2}=\mathrm{CHCl}_{2}$ (Table 2). The latter approximately corresponds to the greatest orbital-orbital $n_{O} \rightarrow \sigma^{*}{ }_{C-H}$ energies.

Interestingly, the lone pair electrons localized on the oxygen atom in the systems where $\mathrm{R}_{2}=\mathrm{CHCl}_{2}$ point toward the $\mathrm{C}-\mathrm{H}$ hydride atom as seen in Figure 3. For the systems where $\mathrm{R}_{2}=\mathrm{CH}_{3}, \mathrm{n}_{\mathrm{O}} \rightarrow \sigma^{*}{ }_{\mathrm{C}-\mathrm{H}}$ orbitals are held much farther apart than in the former species where $\mathrm{Cl}$ substituents enhance the strength of the hydrogen bond. Figure 3 shows an overlap surface-rendered diagram for the interacting $\mathrm{n}_{\mathrm{O}}$ and $\sigma_{\mathrm{C}-\mathrm{H}}{ }_{\mathrm{C}}$ orbitals in pyrrolepyrazinones 22 and 20. It reveals a propensity for the $\mathrm{C}-\mathrm{H}^{\cdots} \mathrm{O}=\mathrm{C}$ bonding for pyrrolopyrazinone 22 , whereas $20\left(\mathrm{R}_{2}=\mathrm{CH}_{3}\right)$ exhibits a weak $n_{O} \rightarrow \sigma^{*}{ }_{C-H}$ interaction with the backside of the $\mathrm{CH}$ antibond.

It seems most likely that the changes observed in the $\mathrm{H}$ bonding can be due to the steric repulsion between oxygen and chlorine atoms. The presence of $\mathrm{H}$-bond depends on geometrical arrangement of the oxygen and hydrogen atoms determined by its repulsion. In $\mathrm{R}_{2}=\mathrm{CHCl}_{2}$, two chlorine atoms are forced to be in the anticlinal configuration with 


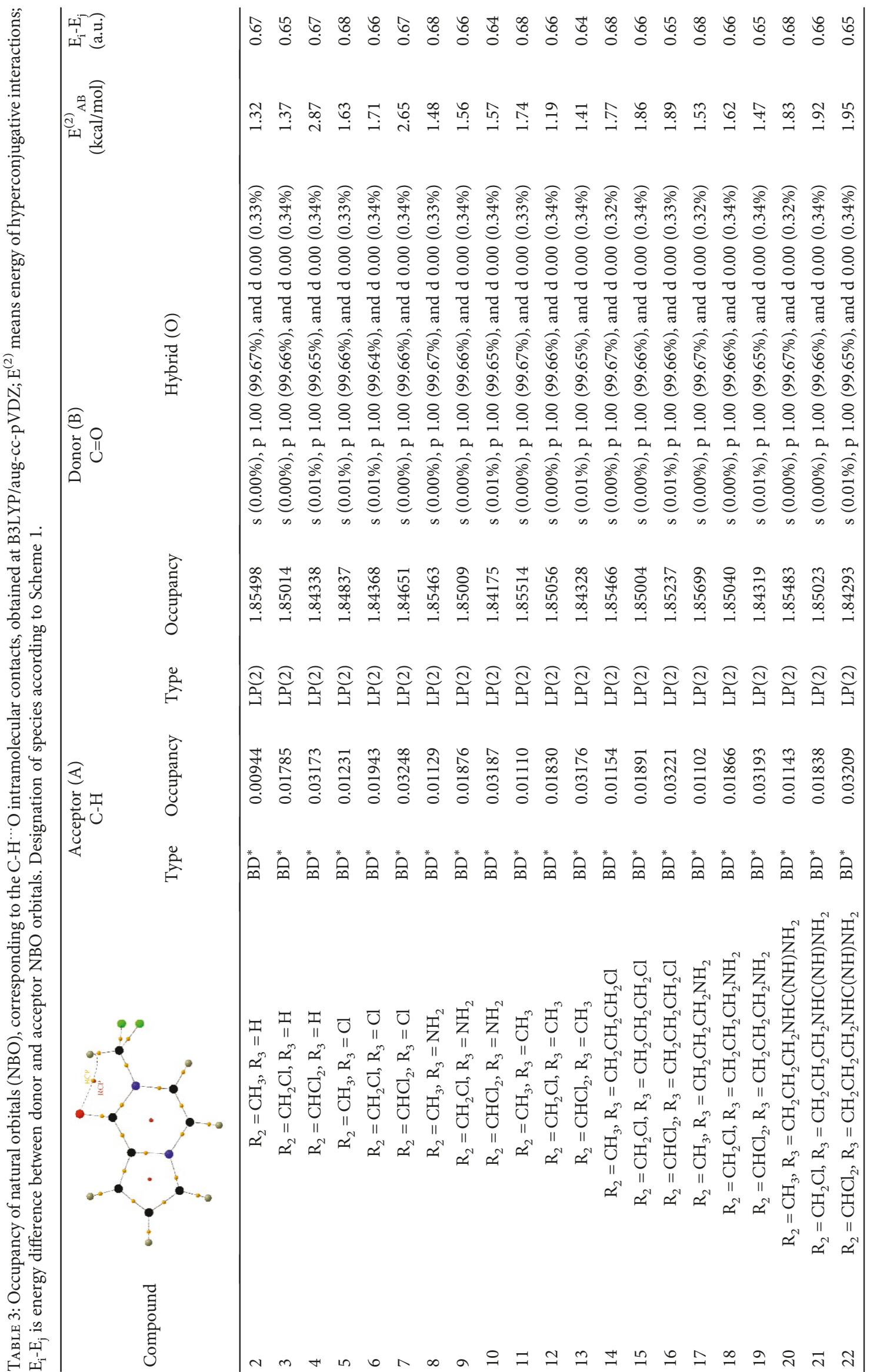




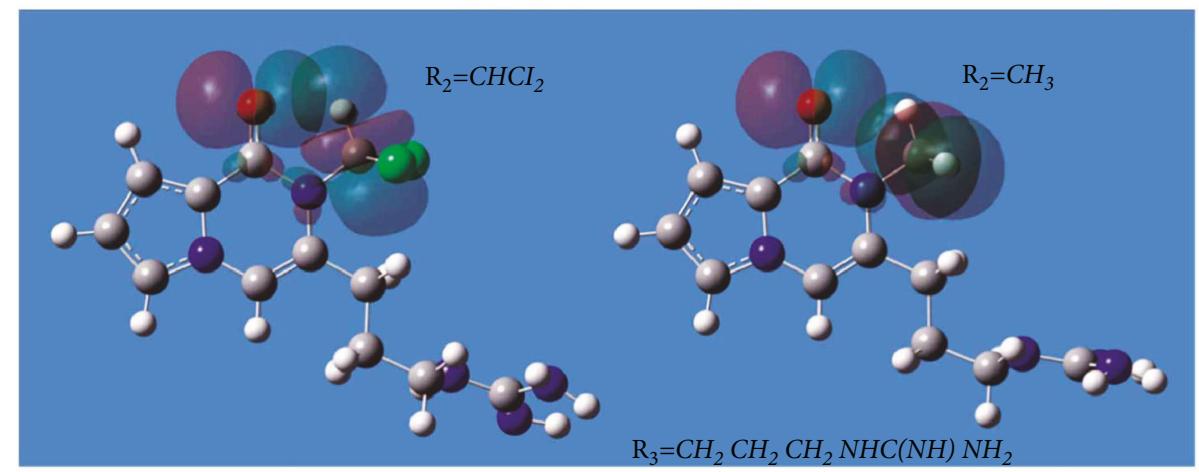

FIGURE 3: NBO overlap interaction surface plot for the bay region of pyrrolopyrazinones $22\left(\mathrm{R}_{2}=\mathrm{CHCl}_{2}\right)$ and $20\left(\mathrm{R}_{2}=\mathrm{CH}_{3}\right)$ showing stabilizing donor-acceptor $\mathrm{n}_{\mathrm{O}} \rightarrow \sigma^{*}{ }_{\mathrm{C}-\mathrm{H}}$ interaction.

respect to oxygen. Such behavior minimizes repulsion, and therefore the $\mathrm{H}$ atom of the $\mathrm{CHCl}_{2}$ group is in a synperiplanar configuration that is favorable for $\mathrm{H}$-bonding.

In $\mathrm{R}_{2}=\mathrm{CH}_{2} \mathrm{Cl}$, the minimal repulsion is present in the antiperiplanar configuration of the oxygen and chlorine atom. This phenomenon forces the synclinal conformation of two hydrogen atoms of $\mathrm{R}_{2}$ with respect to $\mathrm{O}$ atom. It is much less favorable for $\mathrm{H}$-bond formation between $\mathrm{C}=\mathrm{O}$ and $\mathrm{R} 2=\mathrm{CH}_{2} \mathrm{Cl}$.

\subsection{Intramolecular Hydrogen Bond and HOMA Aromaticity} Interrelation. Palusiak et al. [52] revealed the interplay between local aromaticity of a polycyclic aromatic hydrocarbon and the strength of the intramolecular HB. It is also interesting to recognize the role of substituents and the hydrogen bond to stabilize pyrrolopyrazinone molecules analyzed here, particularly the effect of these factors on local aromaticities. It is worth to mention that the local aromaticity analyzed for the numerous systems considered in this study characterizes the aromaticity of a particular ring of the system [53].

The HOMA indices calculated for pyrrole (1), 3,4-dihydropyrrolopyrazinones $(1 \mathrm{a}-\mathrm{c})$, pyrazine (1d), 2-oxopyrazine (1e), and pyrrolopyrazinones (2-22) are shown in Table 1. There are substituents in 2 and 3 positions $\left(R_{2}\right.$ and $\left.R_{3}\right)$ for the species analyzed here: 3,4-dihydropyrrolopyrazinones $(1 \mathrm{a}-\mathrm{c})$ and pyrrolopyrazinones $(2-22)$. Table 1 is divided into two sections; the first section shows the local aromaticity of the pyrrole ring whereas the second section lists the local aromaticity of the pyrazinone ring. $\mathrm{C}-\mathrm{C}$ and $\mathrm{C}-\mathrm{N}$ bond lengths and HOMA values as well as calculated $v_{\mathrm{C}=\mathrm{C}}$ and $v_{\mathrm{C}=\mathrm{O}}$ frequencies are also included.

The HOMA index of pyrrole (1) is 0.833 , whereas local HOMAs of 3,4-dihydropyrrolopyrazinones ( $1 \mathrm{a}-\mathrm{c}$ ) range from 0.876 to 0.885 . The aromaticity of the pyrrole ring in 2-22 moieties varies between 0.848 and 0.905 HOMA units. It is seen that the HOMAs of the pyrrole ring for structures $1 c, 4,7,10,13,16,19$, and 22 where $\mathrm{R}_{2}=\mathrm{CHCl}_{2}$ are higher than those for structures 1a, 2, 5, 8,11,14, 17, and 20, and $1 b, 3,6,9,12,15,18$, and 21 where $\mathrm{R}_{2}=\mathrm{CH}_{3}$ or $\mathrm{CH}_{2} \mathrm{Cl}$, respectively. For instance, the HOMA value for the pyrrole ring of peramine (20) where $\mathrm{R}_{2}=\mathrm{CH}_{3}$ is 0.865 , for the chloromethylene derivative (21) where $\mathrm{R}_{2}=\mathrm{CH}_{2} \mathrm{Cl}$ is 0.869 , and for the dichloromethylene derivative (22) where $\mathrm{R}_{2}=\mathrm{CHCl}_{2}$ is 0.877 a.u.

The local HOMA indices of the pyrrole ring for 3,4-dihydropyrrolopyrazinones $1 \mathrm{a}, 1 \mathrm{~b}$, and $1 \mathrm{c}$ are higher than those of pyrrolopyrazinone 2,3 , and 4 (Table 1). For instance, the HOMA for pyrrolopyrazinones 2 and 3 is 0.848 and 0.852 , respectively, while for 3,4-dihydropyrrolopyrazinone $1 \mathrm{a}$ and $1 \mathrm{~b}$, it is 0.876 and 0.882 , respectively. An analogous situation is observed for residual pairs of pyrrolopyrazinone moieties $\left(\mathrm{R}_{2}=\mathrm{CH}_{2} \mathrm{Cl}\right.$ and $\left.\mathrm{R}_{2}=\mathrm{CH}_{3}\right)$, such as 5 and 6,8 and 9,11 and 12,14 and 15,17 and 18 , and 20 and 21 , as compared with HOMA indices of the pyrrole ring for 3,4-dihydropyrrolopyrazinones $1 \mathrm{a}$ and $1 \mathrm{~b}$ (Table 1 ). This means that the addition of a pyrazinone ring reduces the aromaticity of the pyrrole ring in a pyrrolopyrazinone system as compared with an isolated pyrrole molecule. Aside from the abovementioned pairs of systems, the HOMA index for the pyrrole ring is typically higher for species with the $\mathrm{CH}_{2} \mathrm{Cl}$ substituent than for those where $\mathrm{R}_{2}=\mathrm{CH}_{3}$.

It is worth mentioning that the so-called Clar's rules represent a qualitative description of the aromatic character of a particular ring in a molecule of polycyclic species. These rules classify rings according to their $\pi$-electron structure into aromatic sextets, empty rings, migrating rings, and those with localized double bonds [54]. The HOMA approach enables distinguishing Clar's sextets (very high HOMA close to 1.00 ) and empty rings and those with a localized double bond (low HOMA values). This may be performed by HOMA partitioning in energetic (EN) and geometric (GEO) terms [18]. The EN and GEO contributions express the aromaticity contributions related to a decrease in resonance energy and to an increase in bond length alternation, respectively [29]. These contributions for the species analyzed here are shown in Table 1 . It is seen that the GEO term varies significantly with the $\mathrm{R}_{2}$ substituent, for example for the 2, 3, 4 and 5, 6, 7 triads where $\mathrm{R}_{2}=\mathrm{CH}_{3}, \mathrm{R}_{2}=\mathrm{CH}_{2} \mathrm{Cl}$, and $\mathrm{R}_{2}=\mathrm{CHCl}_{2}$, respectively. The formation of the $\mathrm{C}-\mathrm{H} \cdots \mathrm{O}=\mathrm{C}$ intramolecular hydrogen bond for systems where $\mathrm{R}_{2}=\mathrm{CHCl}_{2}$ leads to a decreased GEO contribution and consequently an increase in the $\mathrm{HOMA}$ value (HOMA = 1 - GEO - EN).

It is concluded based on the results from Table 1 that the HOMA aromaticity of heterocyclic rings is directly related to the structural properties of the $R_{2}$ substituent 
and to the geometry of the $\mathrm{H}^{\cdots} \mathrm{O}$ contact in the chelate ring. It should be noted that HOMA differences for the pair of compounds where $\mathrm{R}_{2}=\mathrm{CH}_{2} \mathrm{Cl}$ or $\mathrm{R}_{2}=\mathrm{CHCl}_{2}$ are small, $\triangle \mathrm{HOMA}=0.002-0.008$. However, a trend is observed that HOMA is greater for species where $\mathrm{R}_{2}=\mathrm{CHCl}_{2}$ than for the ones where $\mathrm{R}_{2}=\mathrm{CH}_{2} \mathrm{Cl}$. It may suggest that the relatively larger stability of the aromatic pyrrole ring in pyrrolepyrazinone moieties where $\mathrm{R}_{2}=\mathrm{CHCl}_{2}$ compared to its $\mathrm{R}_{2}=\mathrm{CH}_{2} \mathrm{Cl}$ counterpart results from the slightly larger aromatic character due to the formation of the $\mathrm{HB}$ chelate ring.

The HOMA index of pyrazine (1d) [55] is 0.985 , whereas HOMA of 2-oxo-pyrazine (1e) is 0.591 . Both heterocycles may be treated as reference moieties. Local aromaticity expressed by HOMA of the pyrazinone ring in moieties 222 varies in a range of $0.400-0.512$. The HOMAs of the pyrazinone ring for structures $4,7,10,13,16,19$, and 22 where $\mathrm{R}_{2}=\mathrm{CHCl}_{2}$ are lower than the HOMAs for structures 2, 5, $8,11,14,17$, and 20 , and $3,6,9,12,15,18$, and 21 where $\mathrm{R}_{2}=\mathrm{CH}_{3}$ or $\mathrm{CH}_{2} \mathrm{Cl}$, respectively. For example, the HOMA value for the pyrazinone ring of peramine (20) where $\mathrm{R}_{2}=\mathrm{CH}_{3}$ is 0.487 , while that for the chloromethylene derivative (21) where $\mathrm{R}_{2}=\mathrm{CH}_{2} \mathrm{Cl}$ is 0.427 . For the dichloromethylene derivative (22) where $\mathrm{R}_{2}=\mathrm{CHCl}_{2}$, it is 0.404 .

It is worth noting that the opposite relationship is observed for the local HOMA aromaticity index of the pyrrole ring; it is greater for $\mathrm{R}_{2}=\mathrm{CHCl}_{2}$ than for $\mathrm{R}_{2}=\mathrm{CH}_{3}$ or $\mathrm{R}_{2}=\mathrm{CH}_{2} \mathrm{Cl}$.

Some attention was paid previously to the intermolecular interactions affecting aromaticity of certain phenol derivatives [56, 57]. It was concluded that an increase in the $\mathrm{H}$-bond strength of phenol derivatives resulted in a decrease in aromaticity. It was also stated that the main structural factor contributing to the decreased aromaticity of the ring resulted mostly from bond length alternations. The increase in GEO leads to a decrease in aromaticity (HOMA diminishes). For the species analyzed here, the local HOMA aromaticity of the pyrazinone ring decreases (Table 1), which is connected with the increase in the GEO and EN terms.

The electron-withdrawing substituents, such as $-\mathrm{CHCl}_{2}$, lead to a local EN increase for pyrazinone that consequently results in the decrease in the corresponding local HOMA index. The lower local aromaticity of the pyrazinone ring may result from the methyl group electron-withdrawing properties that increase if hydrogen atoms are substituted by chlorine atoms. It is also noted, however, that the increase of stability of the other ring, pyrrole, is expressed in the increase of the corresponding local HOMA index. In other words, an increase in the aromaticity of one ring leads to lower aromaticity of the other ring. This result is consistent with the earlier findings for pyrrole and $\mathrm{N}$-methylpyrrole reported by Dubis et al. [9].

Moreover, it is worth noting that the HOMA aromaticity index for the pyrazine ring, $1 \mathrm{~d}$, of 0.985 is greater than that calculated for 2-oxo-pyrazine, 1e, of 0.591. This may be compared with the pyrazinone ring HOMA values for 2, 3, and 4 , equal to $0.466,0.414$, and 0.408 , respectively. An analogous situation is observed for residual pairs of pyrrolopyrazine moieties.
These observations can be concluded in the following way. The $\mathrm{C}-\mathrm{H}^{\cdots} \mathrm{O}$ contact is shorter with higher local HOMA aromaticity of the pyrrole ring and lower HOMA aromaticity of the pyrazinone ring. These interrelated changes may be explained by a decrease in bond length alternation in the pyrrole ring confirmed by a decrease in GEO increments and a decrease in resonance energy of the pyrazinone ring confirmed by an increase in the $\mathrm{EN}$ increment to HOMA.

4.5. Vibrational Properties. Table 1 also shows the IR frequencies of the carbonyl group, $v_{\mathrm{CO}}$, which may be considered as an indicator of $\mathrm{HB}$ interaction. Conventional A$\mathrm{H} \cdots \mathrm{B}$ hydrogen bonds include the bonds formed by main group elements such as $\mathrm{N}, \mathrm{O}, \mathrm{F}, \mathrm{Cl}$, and $\mathrm{Br}$, whereas for weak $\mathrm{H}$-bonds, $\mathrm{C}-\mathrm{H}, \mathrm{P}-\mathrm{H}$, and $\mathrm{Si}-\mathrm{H}$ are often nonconventional proton-donating bonds. Such a situation occurs for the $\mathrm{C}-\mathrm{H}^{\cdots} \mathrm{O}$ hydrogen bonds analyzed here.

$\mathrm{H}$-bond formation affects the stretching band of the $\mathrm{A}-\mathrm{H}$ bond as well as the stretching vibrational mode of the proton-accepting center, that is, the $\mathrm{C}=\mathrm{O}$ group in this study. Current computational studies reveal that the frequency of the $\mathrm{C}=\mathrm{O}$ stretching mode of systems 2, 3, and 4 for which $\mathrm{R}_{2}=\mathrm{CH}_{3}, \mathrm{R}_{2}=\mathrm{CH}_{2} \mathrm{Cl}$, and $\mathrm{R}_{2}=\mathrm{CHCl}_{2}$ ranges from $1669 \mathrm{~cm}^{-1}$ in $2\left(\mathrm{R}_{2}=\mathrm{CH}_{3}\right)$ without intramolecular $\mathrm{C}-\mathrm{H} \cdots \mathrm{O}$ interactions to $1689 \mathrm{~cm}^{-1}$ for system $4\left(\mathrm{R}_{2}=\mathrm{CHCl}_{2}\right)$. The frequency of the $\mathrm{C}=\mathrm{O}$ stretching mode of systems 2, 5, 8, 11, 14, 17, and 20 for which $\mathrm{R}_{2}=\mathrm{CH}_{3}$ ranges from $1674 \mathrm{~cm}^{-1}$ in system 5 to $1664 \mathrm{~cm}^{-1}$ in system 17 .

The frequency of the $\mathrm{C}=\mathrm{O}$ stretching mode of systems 3 , $6,9,12,15,18$, and 21 for which $\mathrm{R}_{2}=\mathrm{CH}_{2} \mathrm{Cl}$ ranges from $1696 \mathrm{~cm}^{-1}$ in system 9 to $1686 \mathrm{~cm}^{-1}$ in system 3 .

The formation of the hydrogen bond leads to an electron density shift from the Lewis base to the Lewis acid unit; for the $\mathrm{C}-\mathrm{H}^{\cdots} \mathrm{O}$ interactions analyzed here; from the lone pairs of oxygen ( $\mathrm{C}=\mathrm{O}$ group) to the $\mathrm{C}-\mathrm{H}$ proton donor. It is expressed as the $\mathrm{n}(\mathrm{O}) \rightarrow \sigma^{*}(\mathrm{CH})$ orbital-orbital overlap in terms of the NBO approach. The latter causes weakening of the $\mathrm{C}=\mathrm{O}$ bond, its elongation, and red shifting of the $v(\mathrm{C}=\mathrm{O})$ stretching vibrational mode. The frequency of the $\mathrm{C}=\mathrm{O}$ stretching mode of systems $4,7,10,13,16,19$, and 22 for which $\mathrm{R}_{2}=\mathrm{CHCl}_{2}$ ranges from $1798 \mathrm{~cm}^{-1}$ in system 13 to $1687 \mathrm{~cm}^{-1}$ in system 19. $v(\mathrm{C}=\mathrm{O})$ is lower for a system in which $\mathrm{R}_{2}=\mathrm{CH}_{2} \mathrm{Cl}$ than for a system where $\mathrm{R}_{2}=\mathrm{CHCl}_{2}$.

Figure 4 presents an experimental and theoretical spectrum of peramine (20) where $\mathrm{R}_{2}=\mathrm{CH}_{3}$ (Figures 4 (a) and 4 (b)) and theoretical spectra of 21 and 22 (Figures 4(c) and $4(\mathrm{~d})$ ) where $\mathrm{R}_{2}=\mathrm{CH}_{2} \mathrm{Cl}$ and $\mathrm{CHCl}_{2}$, respectively.

It has been found on the basis of the previous study [8] that bands within the spectral ranges $1671-1688 \mathrm{~cm}^{-1}$ and $1640-1655 \mathrm{~cm}^{-1}$ are not simple $\mathrm{C}=\mathrm{O}$ or $\mathrm{C}=\mathrm{C}$ stretching modes, but they are the result of the mixing of $\mathrm{C}=\mathrm{O}$ and $\mathrm{C}=\mathrm{C}$ stretching vibrations. The mode $v_{\alpha}$ has $\mathrm{C}=\mathrm{O}$ and $\mathrm{C}=\mathrm{C}$ double bonds with stretching "out of phase" vibration, whereas $v_{\beta}$ is the "in phase" mode (Figure 4(b)).

When $\mathrm{R}_{2}=\mathrm{CHCl}_{2}$, an intramolecular $\mathrm{CH}^{\cdots} \mathrm{O}=\mathrm{C}$ hydrogen bond is formed. This effect causes the shift of $v_{\alpha}$ to higher frequencies $\left(\Delta v \sim 18 \mathrm{~cm}^{-1}\right)$ in comparison with peramine (20). 

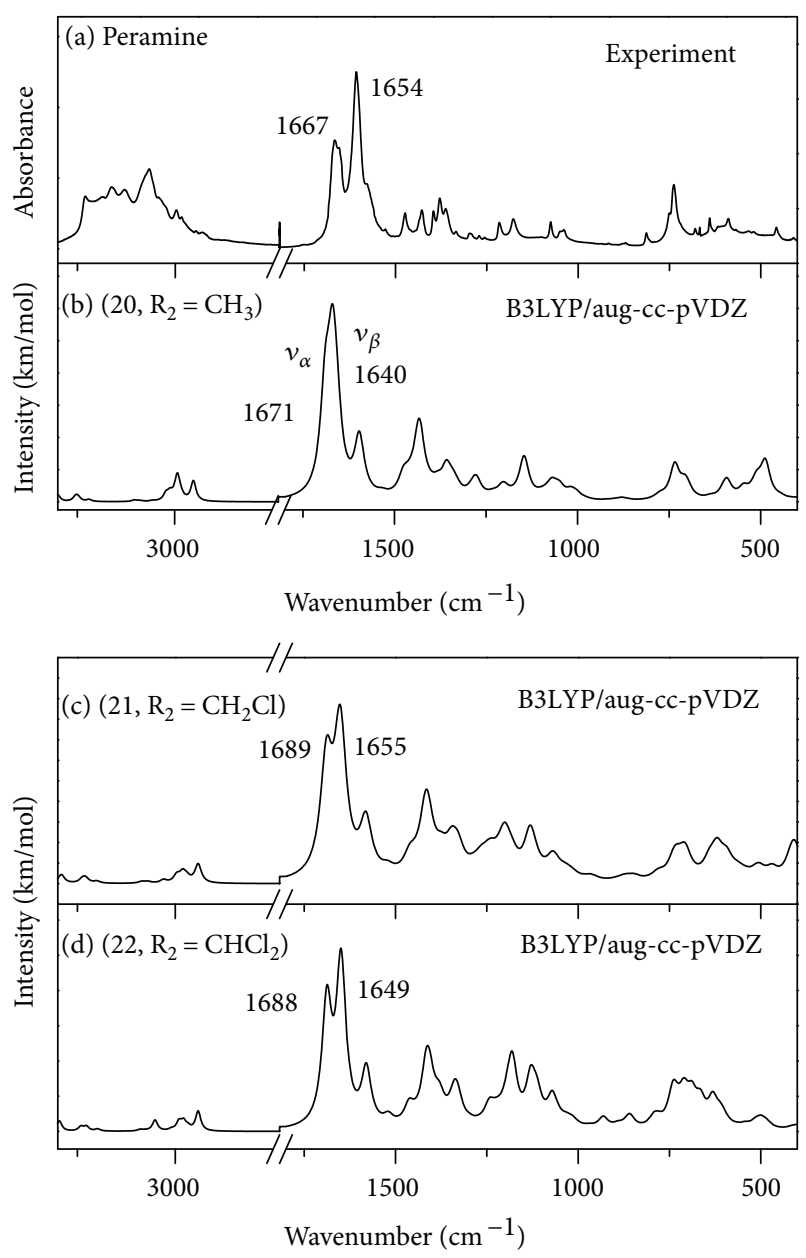

Figure 4: Experimental (a, b) and calculated (c, d) IR spectra (B3LYP/aug-cc-pVDZ level of theory) of peramine $20\left(\mathrm{R}_{2}=\mathrm{CH}_{3}\right)$, $21\left(\mathrm{R}_{2}=\mathrm{CH}_{2} \mathrm{Cl}\right)$, and $22\left(\mathrm{R}_{2}=\mathrm{CHCl} 2\right)$ according to Scheme 1 .

It seems that $v_{\mathrm{C}=\mathrm{O}}$ increases with the $\mathrm{C}-\mathrm{H}^{\cdots} \mathrm{O}=\mathrm{C}$ distance decrease (Table 2). It could be explained as follows: the greater the chelate ring tension, the higher $v_{\mathrm{C}=\mathrm{O}}$. The carbonyl group is $\mathrm{sp}^{2}$ hybridized $\left(120^{\circ}\right)$. Bending the $\mathrm{C}-\mathrm{H}^{\cdots} \mathrm{O}$ toward each other from $116.63^{\circ}$ in 20 to $112.91^{\circ}$ in 22 results in changes in carbonyl carbon hybridization that leads to a strengthening of the $\mathrm{C}=\mathrm{O}$ bond and weakening of the adjacent C-C bond.

\section{Conclusions}

Pyrrolo[1,2-a]pyrazin-1(2H)-ones as an important class of natural organic compounds were analyzed here. The emphasis was put on structures of these species and on factors which determine their unique properties and play a crucial role in numerous reactions, also those which are important in ecology.

For the pyrrolopyrazinone derivatives analyzed here, formation of the intramolecular $\mathrm{C}-\mathrm{H}^{\cdots} \mathrm{O}$ hydrogen bond is observed. In general, geometrical and NBO criteria confirm the existence of such interactions for all systems since the $\mathrm{H}^{\cdots} \mathrm{O}$ distances for all of them are shorter than the corresponding sum of hydrogen and oxygen van der Waals radii as well as for all species in which $n_{O} \rightarrow \sigma^{*}{ }_{C-H}$ orbital-orbital overlap is observed with the corresponding interaction energy of $1.19-2.87 \mathrm{kcal} / \mathrm{mol}$. However, for certain species (those with the $\mathrm{R}_{2}=\mathrm{CH}_{2} \mathrm{Cl}$ substituent and some of the systems where $\mathrm{R}_{2}=\mathrm{CH}_{3}$ ), the QTAIM approach does not detect the existence of the hydrogen bond; $\mathrm{H}^{\cdots} \mathrm{O}$ bond paths are not observed for these systems. It is seen that the substitution of the hydrogen atoms by chlorine atoms enhances the strength of the hydrogen bond; the approximate strength order of the hydrogen bond is observed here according to the following types of $\mathrm{R}_{2}$ groups: $\mathrm{CHCl}_{2}>\mathrm{CH}_{2} \mathrm{Cl}>\mathrm{CH}_{3}$.

The changes observed in the $\mathrm{H}$-bonding can be due to the steric repulsion between oxygen and chlorine atoms. The presence of $\mathrm{H}$-bond depends on the geometrical arrangement of the oxygen and hydrogen atoms determined by its repulsion.

The aromaticity changes are discussed here in terms of the HOMA index and its EN and GEO components. The shortest $\mathrm{C}-\mathrm{H}{ }^{\cdots} \mathrm{O}=\mathrm{C}$ contact is related to a higher $v_{\mathrm{C}=\mathrm{O}}$ value.

\section{Conflicts of Interest}

The authors declare that they have no conflicts of interest.

\section{Acknowledgments}

Calculations were carried out in the Warsaw Supercomputer Center (ICM) (G53-7).

\section{References}

[1] D. D. Rowan, M. B. Hunt, and D. L. Gaynor, "Peramine, a novel insect feeding deterrent from ryegrass infected with the endophyte Acremonium loliae," Journal of the Chemical Society, Chemical Communications, no. 12, pp. 935-936, 1986.

[2] A. Koulman, G. A. Lane, M. J. Christensen, K. Fraser, and B. A. Tapper, "Peramine and other fungal alkaloids are exuded in the guttation fluid of endophyte-infected grasses," Phytochemistry, vol. 68, no. 3, pp. 355-360, 2007.

[3] D. Pańka, D. Piesik, M. Jeske, and A. Baturo-Cieśniewska, "Production of phenolics and the emission of volatile organic compounds by perennial ryegrass (Lolium perenne L.)/Neotyphodium lolii association as a response to infection by Fusarium poae," Journal of Plant Physiology, vol. 170, no. 11, pp. 1010-1019, 2013.

[4] C. L. Schardl, S. Florea, J. Pan, P. Nagabhyru, S. Bec, and P. J. Calie, "The epichloae: alkaloid diversity and roles in symbiosis with grasses," Current Opinion in Plant Biology, vol. 16, no. 4, pp. $480-488,2013$.

[5] M. Kłyś, "Feeding inhibitors in pest control: effect of herb additions to food on the population dynamics of the lesser grain borer Rhyzopertha dominica F.(Coleoptera, Bostrychidae)," Polish Journal of Ecology, vol. 52, pp. 575-581, 2004.

[6] J. W. Spatafora and K. E. Bushley, "Phylogenomics and evolution of secondary metabolism in plant-associated fungi," Current Opinion in Plant Biology, vol. 26, pp. 37-44, 2015.

[7] A. Łapiński and A. T. Dubis, "A DFT/TD-DFT study for the ground and excited states of peramine and some pyrrolopyrazinone compounds," Journal of Physical Organic Chemistry, vol. 22, no. 11, pp. 1058-1064, 2009. 
[8] A. T. Dubis and A. Łapiński, "Spectroscopic and theoretical study on peramine and some pyrrolopyrazinone compounds," Vibrational Spectroscopy, vol. 49, no. 2, pp. 265-273, 2009.

[9] A. T. Dubis, P. Stasiewicz, K. Pogorzelec-Glaser, and A. Łapiński, "Can 2-acylpyrroles form an intramolecular hydrogen bond?," Journal of Physical Organic Chemistry, vol. 28, no. 10, pp. 652-662, 2015.

[10] T. M. Krygowski, M. K. Cyrański, Z. Czarnocki, G. Häfelinger, and A. R. Katritzky, "Aromaticity: a theoretical concept of immense practical importance," Tetrahedron, vol. 56, no. 13, pp. 1783-1796, 2000.

[11] Z. Chen, C. S. Wannere, C. Corminboeuf, R. Puchta, and P. von Ragué Schleyer, "Nucleus-independent chemical shifts (NICS) as an aromaticity criterion," Chemical Reviews, vol. 105, no. 10, pp. 3842-3888, 2005.

[12] M. K. Cyrański, "Energetic aspects of cyclic pi-electron delocalization: evaluation of the methods of estimating aromatic stabilization energies," Chemical Reviews, vol. 105, no. 10, pp. 3773-3811, 2005.

[13] C. W. Bird, "A new aromaticity index and its application to five-membered ring heterocycles," Tetrahedron, vol. 41, no. 7, pp. 1409-1414, 1985.

[14] T. Heine, C. Corminboeuf, and G. Seifert, "The magnetic shielding function of molecules and pi-electron delocalization," Chemical Reviews, vol. 105, no. 10, pp. 3889-3910, 2005.

[15] J. Kruszewski and T. M. Krygowski, "Definition of aromaticity basing on the harmonic oscillator model," Tetrahedron Letters, vol. 13, no. 36, pp. 3839-3842, 1972.

[16] T. M. Krygowski, A. Ciesielski, C. W. Bird, and A. Kotschy, "Aromatic character of the benzene ring present in various topological environments in benzenoid hydrocarbons. Nonequivalence of indices of aromaticity," Journal of Chemical Information and Modeling, vol. 35, no. 2, pp. 203-210, 1995.

[17] T. M. Krygowski, "Crystallographic studies of inter- and intramolecular interactions reflected in aromatic character of .pi.-electron systems," Journal of Chemical Information and Computer Sciences, vol. 33, no. 1, pp. 70-78, 1993.

[18] T. M. Krygowski and M. Cyrański, "Separation of the energetic and geometric contributions to the aromaticity of $\pi$-electron carbocyclics," Tetrahedron, vol. 52, no. 5, pp. 1713-1722, 1996.

[19] A. E. Reed, L. A. Curtiss, and F. Weinhold, "Intermolecular interactions from a natural bond orbital, donor-acceptor viewpoint," Chemical Reviews, vol. 88, no. 6, pp. 899-926, 1988.

[20] M. J. Frisch, G. W. Trucks, H. B. Schlegel et al., Gaussian 09, Gaussian Inc., Wallingford, CT, USA, 2009.

[21] R. A. Kendall, T. H. Dunning Jr., and R. J. Harrison, "Electron affinities of the first-row atoms revisited. Systematic basis sets and wave functions," The Journal of Chemical Physics, vol. 96, no. 9, pp. 6796-6806, 1992.

[22] D. E. Woon and T. H. Dunning Jr., "Gaussian basis sets for use in correlated molecular calculations. III. The atoms aluminum through argon," The Journal of Chemical Physics, vol. 98, no. 2, pp. 1358-1371, 1993.

[23] K. Kim and K. D. Jordan, "Comparison of density functional and MP2 calculations on the water monomer and dimer," The Journal of Chemical Physics, vol. 98, no. 40, pp. 1008910094, 1994.

[24] P. J. Stephens, F. J. Devlin, C. F. Chabalowski, and M. J. Frisch, "Ab initio calculation of vibrational absorption and circular dichroism spectra using density functional force fields," The
Journal of Physical Chemistry, vol. 98, no. 45, pp. 1162311627, 1994.

[25] A. P. Scott and L. Radom, "Harmonic vibrational frequencies: an evaluation of Hartree-Fock, Møller-Plesset, quadratic configuration interaction, density functional theory, and semiempirical scale factors," The Journal of Physical Chemistry, vol. 100, no. 41, pp. 16502-16513, 1996.

[26] F. Biegler-König, J. Schönbohm, and D. Bayles, “AIM2000 - A Program to Analyze and Visualize Atoms in Molecules," Journal of Computational Chemistry, vol. 22, no. 5, pp. 545-559, 2001.

[27] R. Bader, Atoms in Molecules, a Quantum Theory, Oxford University Press, Oxford, UK, 1990.

[28] I. Rozas, I. Alkorta, and J. Elguero, "Behavior of ylides containing $\mathrm{N}, \mathrm{O}$, and $\mathrm{C}$ atoms as hydrogen bond acceptors," Journal of the American Chemical Society, vol. 122, no. 45, pp. 1115411161, 2000.

[29] S. J. Grabowski, "What is the covalency of hydrogen bonding?," Chemical Reviews, vol. 111, no. 4, pp. 2597-2625, 2011.

[30] T. M. Krygowski and M. K. Cyrański, "Structural aspects of aromaticity," Chemical Reviews, vol. 101, no. 5, pp. 13851420, 2001.

[31] B. Jeziorski, R. Moszynski, and K. Szalewicz, "Perturbation theory approach to intermolecular potential energy surfaces of van der Waals complexes," Chemical Reviews, vol. 94, no. 7, pp. 1887-1930, 1994.

[32] G. A. Jeffrey, An Introduction to Hydrogen Bonding, Oxford University Press, New York, 1997.

[33] P. Politzer, J. S. Murray, and T. Clark, "Halogen bonding: an electrostatically-driven highly directional noncovalent interaction," Physical Chemistry Chemical Physics, vol. 12, no. 28, pp. 7748-7757, 2010.

[34] A. Bondi, "van der Waals Volumes and Radii," Journal of Physical Chemistry, vol. 68, no. 3, pp. 441-451, 1964.

[35] C. Gatti, E. May, R. Destro, and F. Cargnoni, "Fundamental properties and nature of $\mathrm{CH} \cdot \mathrm{O}$ interactions in crystals on the basis of experimental and theoretical charge densities. The Case of 3,4-Bis(dimethylamino)-3-cyclobutene-1,2-dione (DMACB) Crystal," Journal of Physical Chemistry A, vol. 106, no. 11, pp. 2707-2720, 2002.

[36] G. Gilli and P. Gilli, The nature of the hydrogen bond: outline of a comprehensive hydrogen bond theory, Oxford University Press, New York, NY, USA, 2009.

[37] J. J. Novoa, M.-H. Whangbo, and J. M. Williams, "Interaction energies associated with short intermolecular contacts of $\mathrm{C}-\mathrm{H}$ bonds. Structure and energetics of the interaction between $\mathrm{CH}_{4}$ and $\mathrm{CN}^{-}$," Chemical Physics Letters, vol. 177, no. 4-5, pp. 483-490, 1991.

[38] G. R. Desiraju, "Hydrogen bridges in crystal engineering: interactions without borders," Accounts of Chemical Research, vol. 35, no. 7, pp. 565-573, 2002.

[39] P. Baillargeon, T. Lussier, and Y. L. Dory, "Hydrogen bonds between acidic protons from alkynes $(\mathrm{C}-\mathrm{H} \cdots \mathrm{O})$ and amides $(\mathrm{N}-\mathrm{H}$... $\mathrm{O})$ and carbonyl oxygen atoms as acceptor partners," Journal of Crystallography, vol. 2014, Article ID 371629, 5 pages, 2014.

[40] T. Steiner and G. R. Desiraju, "Distinction between the weak hydrogen bond and the van der Waals interaction," Chemical Communications, vol. 8, no. 8, pp. 891-892, 1998.

[41] O. Mó, M. Yáñez, and J. Elguero, "Cooperative (nonpairwise) effects in water trimers: An ab initio molecular orbital study," 
The Journal of Chemical Physics, vol. 97, no. 9, pp. 6628-6638, 1992.

[42] P. L. A. Popelier, Atoms in Molecules. An introduction, Prentice, Pearson Education, Essex, England, 2000.

[43] S. J. Grabowski, "Hydrogen bonding strength-measures based on geometric and topological parameters," Journal of Physical Organic Chemistry, vol. 17, no. 1, pp. 18-31, 2004.

[44] F. Weinhold, "Nature of H-bonding in clusters, liquids, and enzymes: an ab initio, natural bond orbital perspective," Journal of Molecular Structure: THEOCHEM, vol. 398-399, pp. 181-197, 1997.

[45] A. Allerhand and P. Von Rague Schleyer, "A survey of C-H groups as proton donors in hydrogen bonding," Journal of the American Chemical Society, vol. 85, no. 12, pp. 1715-1723, 1963.

[46] S. Tsuzuki, T. Uchimaru, K. Tanabe, and T. Hirano, "Conformational analysis of 1,2-dimethoxyethane by ab initio molecular orbital and molecular mechanics calculations: stabilization of the TGG' rotamer by the $1,5 \mathrm{CH} 3 / \mathrm{O}$ nonbonding attractive interaction," The Journal of Physical Chemistry, vol. 97, no. 7, pp. 1346-1350, 1993.

[47] I. V. Alabugin, M. Manoharan, S. Peabody, and F. Weinhold, "Electronic basis of improper hydrogen bonding: a subtle balance of hyperconjugation and rehybridization," Journal of the American Chemical Society, vol. 125, no. 19, pp. 5973-5987, 2003.

[48] Y. Yang, W. Zhang, and X. Gao, "Blue-shifted and red-shifted hydrogen bonds: theoretical study of the $\mathrm{CH} 3 \mathrm{CHO}$. . HNO complexes," International Journal of Quantum Chemistry, vol. 106, no. 5, pp. 1199-1207, 2006.

[49] I. V. Alabugin and M. Manoharan, "Rehybridization as a general mechanism for maximizing chemical and supramolecular bonding and a driving force for chemical reactions," Journal of Computational Chemistry, vol. 28, no. 1, pp. 373-390, 2006.

[50] S. J. Grabowski and J. M. Ugalde, "Bond paths show preferable interactions: $\mathrm{ab}$ initio and QTAIM studies on the $\mathrm{X}-\mathrm{H} \cdots \pi$ hydrogen bond," Journal of Physical Chemistry A, vol. 114, no. 26, pp. 7223-7229, 2010.

[51] I. Alkorta, J. Elguero, and S. J. Grabowski, "How to determine whether intramolecular $\mathrm{H} \cdots \mathrm{H}$ interactions can be classified as dihydrogen bonds," Journal of Physical Chemistry A, vol. 112, no. 12, pp. 2721-2727, 2008.

[52] M. Palusiak, S. Simon, and M. Solà, "Interplay between intramolecular resonance-assisted hydrogen bonding and local aromaticity. II. 1,3-dihydroxyaryl-2-aldehydes," Journal of Organic Chemistry, vol. 74, no. 5, pp. 2059-2066, 2009.

[53] J. Poater, R. Visser, M. Solà, and F. M. Bickelhaupt, "Polycyclic benzenoids: why kinked is more stable than straight," Journal of the Organic Chemistry, vol. 72, no. 4, pp. 1134-1142, 2007.

[54] E. Clar, The Aromatic Sextet, Wiley, London, NY, 1972.

[55] C. P. Frizzo and M. A. P. Martins, "Aromaticity in heterocycles: new HOMA index parametrization," Structural Chemistry, vol. 23, no. 2, pp. 375-380, 2012.

[56] T. M. Krygowski, H. Szatylowicz, and J. E. Zachara, "How Hbonding affects aromaticity of the ring in variously substituted phenol complexes with bases. 4. molecular geometry as a source of chemical information," Journal of Chemical Information and Computer Sciences, vol. 44, no. 6, pp. 2077-2082, 2004.

[57] A. R. Katritzky, M. Karelson, and A. P. Wells, "Aromaticity as a quantitative concept. 6 . Aromaticity variation with molecular environment," Journal of Organic Chemistry, vol. 61, no. 5, pp. 1619-1623, 1996. 

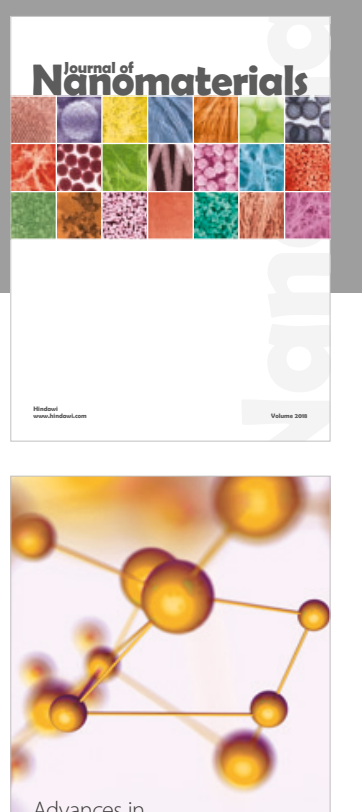

Physical Chemistry
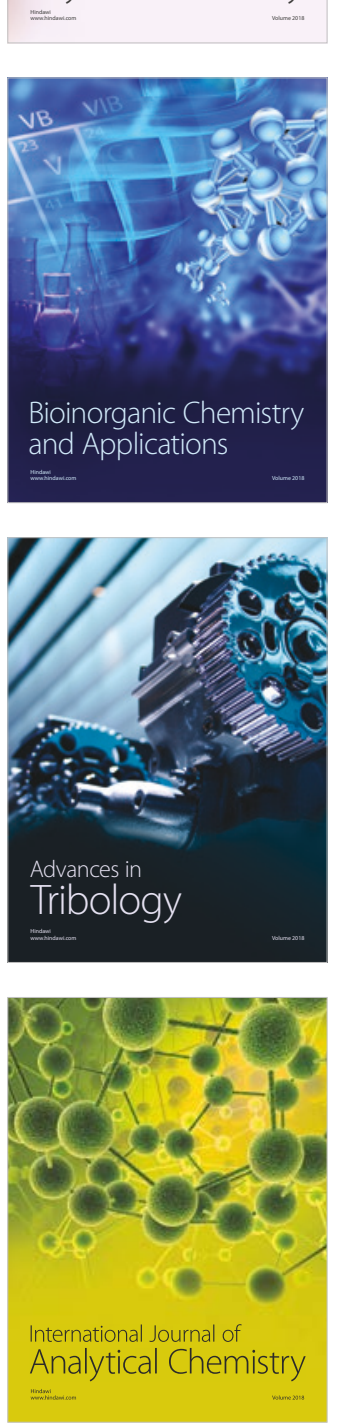

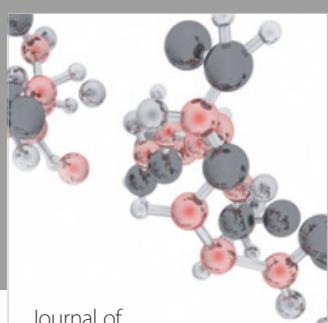

Analytical Methods

in Chemistry

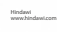

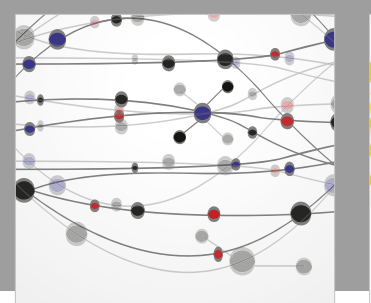

The Scientific World Journal

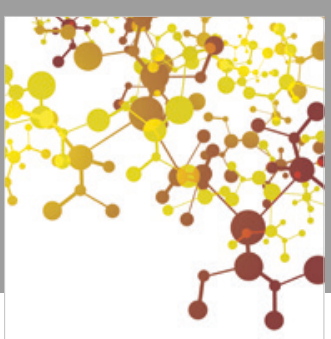

Journal of

Applied Chemistry
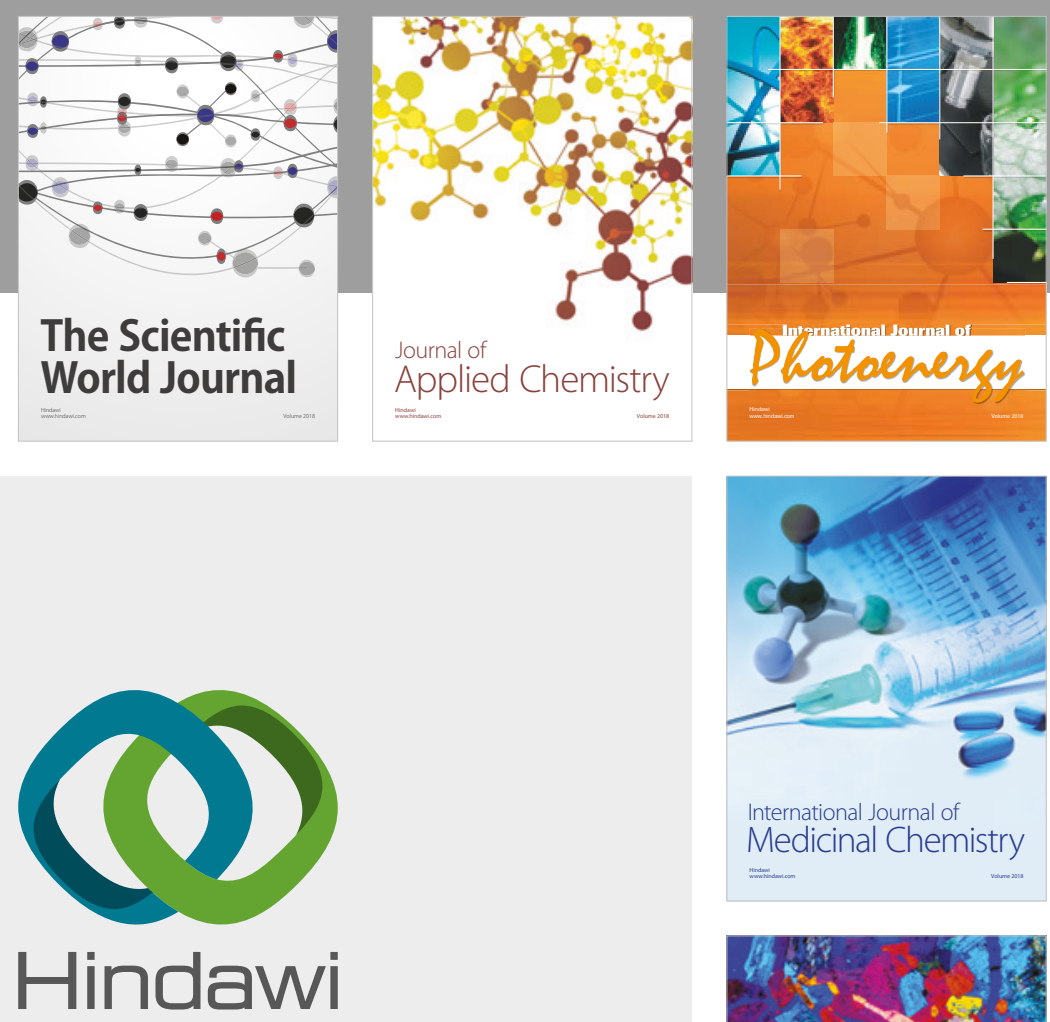

Submit your manuscripts at

www.hindawi.com
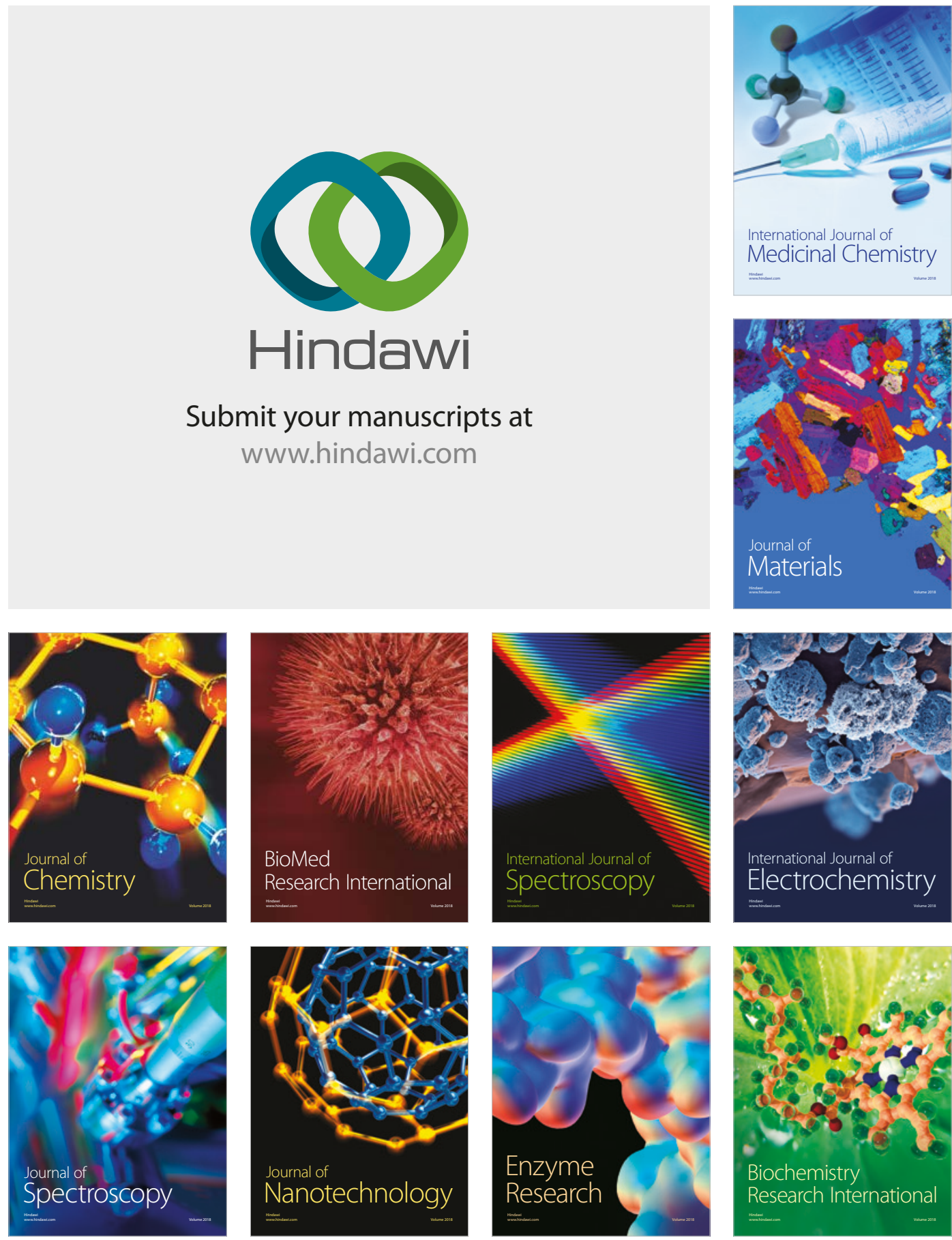
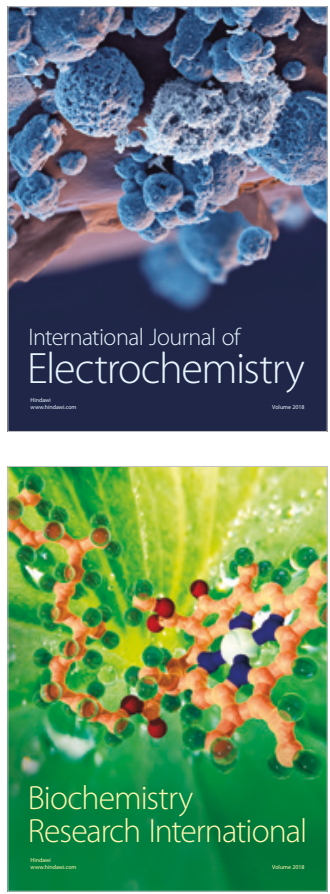